\title{
Tiebout's Tale in Spatial Economies: Entrepreneurship, Self-Selection, and Efficiency*
}

\author{
Hideo Konishi ${ }^{\dagger}$
}

November 30, 2007

\begin{abstract}
This paper establishes the existence and efficiency of equilibrium in a local public goods economy with spatial structures by formalizing Hamilton's (1975 Urban Studies) elaboration of Tiebout's (1956 JPE) tale. We use a well-known equilibrium concept from Rothschild and Stiglitz (1976, QJE) in a market with asymmetric information, and show that Hamilton's zoning policy plays an essential role in proving the existence and efficiency of equilibrium. We use an idealized large economy following Ellickson, Grodal, Scotchmer and Zame (1999, Econometrica) and Allouch, Conley and Wooders (2004). Our theorem is directly applicable to the existence and efficiency of a discrete spatial approximation of mono- or multi-centric city equilibria in an urban economy with commuting time costs, even if we allow the existence of multiple qualities of (collective) residences, when externalities due to traffic congestion are not present.
\end{abstract}

*I thank Jan Brueckner, John Conley, Masa Fujita, Atsushi Kajii, Kazuya Kamiya, Se-il Mun, Jaime Luque, Frederic Robert-Nicoud, Alain Trannoy, and Myrna Wooders for their comments and encouragements, and Frank Georges for his research assistance. I especially thank two anonymous referees and an associate editor of the journal for their helpful comments and suggestions. My intellectual debt to Marcus Berliant is obvious. All errors are, of course, my own.

${ }^{\dagger}$ Department of Economics, Boston College hideo.konishi@bc.edu 
It is useful in closing to restate the problem as Samuelson (1954) sees it:

"However, no decentralized pricing system can serve to determine optimally these levels of collective consumption. . . ."

It is the contention of this article that, for a substantial portion of collective or public goods, this problem does have a conceptual solution. (Charles M. Tiebout, "A Pure Theory of Local Public Expenditure," Journal of Political Economy LXIV, 1956, p. 424)

\section{Introduction}

In his celebrated paper published a half century ago, Tiebout (1956) argued that although Samuelsonian pure public goods may be underprovided due to consumers' free-riding incentives in reporting preferences, examples of pure public goods are very rare, and impure local public goods can be provided efficiently (efficiency) by consumers' revealed preferences through voting with feet (self-selection) and competition among jurisdictions (entrepreneurship).

Recently, Ellickson, Grodal, Scotchmer, and Zame (1999) ${ }^{1}$ and Allouch, Conley, and Wooders (2004) provide nice formalizations of Tiebout's idea, proving the existence and Pareto efficiency of Tiebout equilibrium in the exact sense. ${ }^{2}$ According to these papers, if the number of jurisdictions is very large, there is no spillover effect across jurisdictions, jurisdiction managers maximize profits, and the price system is complete for every possible jurisdiction type, then: there exists a Tiebout equilibrium, and every Tiebout equilibrium

\footnotetext{
${ }^{1}$ As they say in their paper, Ellickson et al. (1999) deal with a club economy, in which consumers are allowed to join multiple clubs. However, if we impose a single-membership constraint, their model becomes a standard local public goods model with finite public projects and infinite consumer types. Allouch et al. (2004) deal with local public goods with infinite public projects and finite consumer types.

${ }^{2}$ Wooders $(1978,1980)$ considers finite population cases. The former paper shows the existence and efficiency of equilibrium in the exact sense when total population can be exactly divided up into communities of optimal size. The latter shows the existence and efficiency (core convergence) of equilibrium in approximation for large finite economies. Ellickson et al. (1999) and Allouch et al. (2004), in contrast, show the existence and efficiency of equilibrium in the exact sense with a continuum of consumers when each jurisdiction population is finite.
} 
is Pareto efficient. ${ }^{3}$ They thus provide a rigorous theoretical foundation for Tiebout's tale.

However, as are many papers in the literature that provide support for Tiebout's tale, these papers are still not satisfactory, in two ways, for the analysis of a local public goods economy. First, they do not consider spatial elements. ${ }^{4}$ In his original paper, Tiebout says that housing developers' actions adjust the population of (suburban) communities to an efficient size. ${ }^{5}$ Since suburbanization and a voluntary sorting process make the case in the real world for Tiebout's tale, it seems important for any model to take into account both spatial considerations and the actions of housing developers. Also, as pointed out by Hamilton (1975), in US suburbs, jurisdictions' expenses are financed by property taxes, especially taxes on housing. Thus, the model needs to include land in order to justify Tiebout's tale in the real world. More globally, consumers may care about the climates and geographical features of locations (say, Boston or Los Angeles). Even within the same metropolitan area, they may have preferences for the seaside or the mountains (say, in San Diego). Finally, Tiebout assumes that there is no restriction due to employment opportunity. ${ }^{6}$ This is certainly a very strong assumption if we consider modern American suburbs, where consumers undeniably consider the nearby job opportunities and commuting time when choosing where to live; it seems almost contradictory once spatial elements are introduced in the model. Thus, it is intriguing to know if Tiebout's tale would work without such a strong assumption.

Second, many papers in the literature including Ellickson et al. (1999) and Allouch et al. (2004) assume (implicitly or explicitly) that the price system

\footnotetext{
${ }^{3}$ Bewley (1981) made thorough criticisms of Tiebout's tale. By providing a sequence of counterexamples, he argued convincingly that Tiebout's tale is supportable only in a trivial local public service economy that is essentially the same as a private good economy. However, he assumes that the number of jurisdictions is finite. This is the main reason that Bewley (1981) obtains a very negative result.

${ }^{4}$ In the club goods model, spatial elements are less important than in the local public goods model. Thus, unless their theorem is applied to a local public goods economy, the first point does not apply to Ellickson et al. (1999). The second point (stated below) will be relevant for both papers.

${ }^{5}$ Discussions after his Assumption 7. Assumption 7 states that "communities below the optimum size seek to attract new residents to lower average costs. Those above optimal size do just the opposite. Those at an optimum try to keep their population constant."

${ }^{6}$ His Assumption 4: "Restrictions due to employment opportunities are not considered. It may be assumed that all persons are living on dividend income."
} 
is complete: that is, there are markets for all potential jurisdiction types in addition to the jurisdiction types that are observed in equilibrium. This is obviously an unrealistic and unsatisfactory assumption. In this paper, using an equilibrium concept from Rothschild and Stiglitz (1976), we successfully drop the complete market assumption while preserving efficiency of equilibrium.

We provide a spatial model and an equilibrium concept that answer the above considerations. We show that these considerations in themselves do not speak against Tiebout's tale. We prove both existence and efficiency of equilibrium by extending the approaches of Ellickson et al. (1999) and Allouch et al. (2004). The key assumptions for our positive result are (i) a large number of jurisdictions in each physical location; (ii) Hamilton's (1975) zoning policy which makes crowding effects fiscally anonymous; and (iii) free entry by potential profit-maximizing jurisdiction managers. We also show as a corollary of our theorem that a closed-economy, finite-location monocentric city has an equilibrium even when quality of housing is a variable determined by developers and collective houses (condos/apartments) are allowed, and that the equilibrium is efficient in the absence of externalities due to traffic congestion.

In the rest of this section, we discuss the above two considerations in more detail. In Section 2, we briefly explain how efficiency of equilibrium is achieved with our equilibrium concept. In Section 3, we present our model, our concept of equilibrium, and the result (Theorem). Section 4 provides the sketch of the proof. Section 5 closes the paper with possible extensions, applications to urban economics, and cautious remarks on the implications of our result.

\subsection{Spatial Considerations}

Several papers discuss efficiency of equilibrium while considering some of the following spatial aspects: (i) the effects of property taxes and zoning policies and (ii) differences in physical location and/or commuting costs.

In the U.S., the main revenue source of local jurisdictions is property tax, which is mainly a tax on housing values. In a beautiful but informal paper, Hamilton (1975) discusses efficiency and self-selection in equilibrium of a model that includes housing developers and land. Hamilton argues that if the jurisdictions are profit-maximizing land developers, complete segregation by preferences and efficiency of equilibrium are achieved simultaneously if the jurisdictions adopt zoning policies (minimum lot size restrictions). ${ }^{7}$ A zoning

\footnotetext{
${ }^{7}$ A paper by Sonstelie and Portney (1978) is similar to Hamilton's with some more details.
} 
policy eliminates distortion, prevents free-riding, and achieves segregation of consumers by their preferences. This insightful story supplements Tiebout's original tale and makes it applicable to spatial models. ${ }^{8}$

\section{[Figure 1.]}

We also introduce heterogeneous locations into the model so that we can include commuting costs and preferences over physical locations. We assume that there are many jurisdictions in each physical location. Thus, within a jurisdiction, land is assumed to be homogeneous (see Figure 1); our framework in the current paper cannot handle heterogeneous land within a jurisdiction. ${ }^{9}$ Note also that wage rates vary in different locations due to different levels of productivity. As we have said above, Tiebout (1956) assumes that there are no restrictions arising from employment opportunities (his assumption 4). Buchanan and Wagner (1970), Buchanan and Goetz (1972), and Flatters, Henderson, and Mieszkowski (1974) elaborate Tiebout's statement by claiming that allowing individuals to choose their location of employment precludes efficiency of equilibrium since "voting with feet" is a process of utility equalization rather than one of marginal product equalization. However, these models have a predetermined finite number of jurisdictions, and do not allow for the possibility of creating a new jurisdiction. In our model, there are many small jurisdictions and entry of new jurisdictions is allowed implicitly. In such a scenario, we can show that spatial wage differentials play no role in achieving efficiency of equilibrium.

\subsection{Equilibrium Concept}

Besides spatial location, another point we address in this paper is the concept of equilibrium. Although Ellickson et al. (1999) and Allouch et al. (2004) provide positive results (existence and the first welfare theorem), their equilibrium concepts assume that agents are price takers and that the market is complete in the sense that every possible jurisdiction type (or jurisdiction policy package: population, tax rate, and local public goods) has a price regardless of the

\footnotetext{
${ }^{8}$ In his footnote 15 , Hamilton also says that zoning policy would achieve efficiency even with heterogeneous locations in the context of a monocentric city briefly.

${ }^{9}$ Henderson (1974) proposed a model of system of cities, in which there are many specialized monocentric cities trading with each other. In contrast, our model deal with smaller jurisdictions, and there are many jurisdictions within a monocentric city.
} 


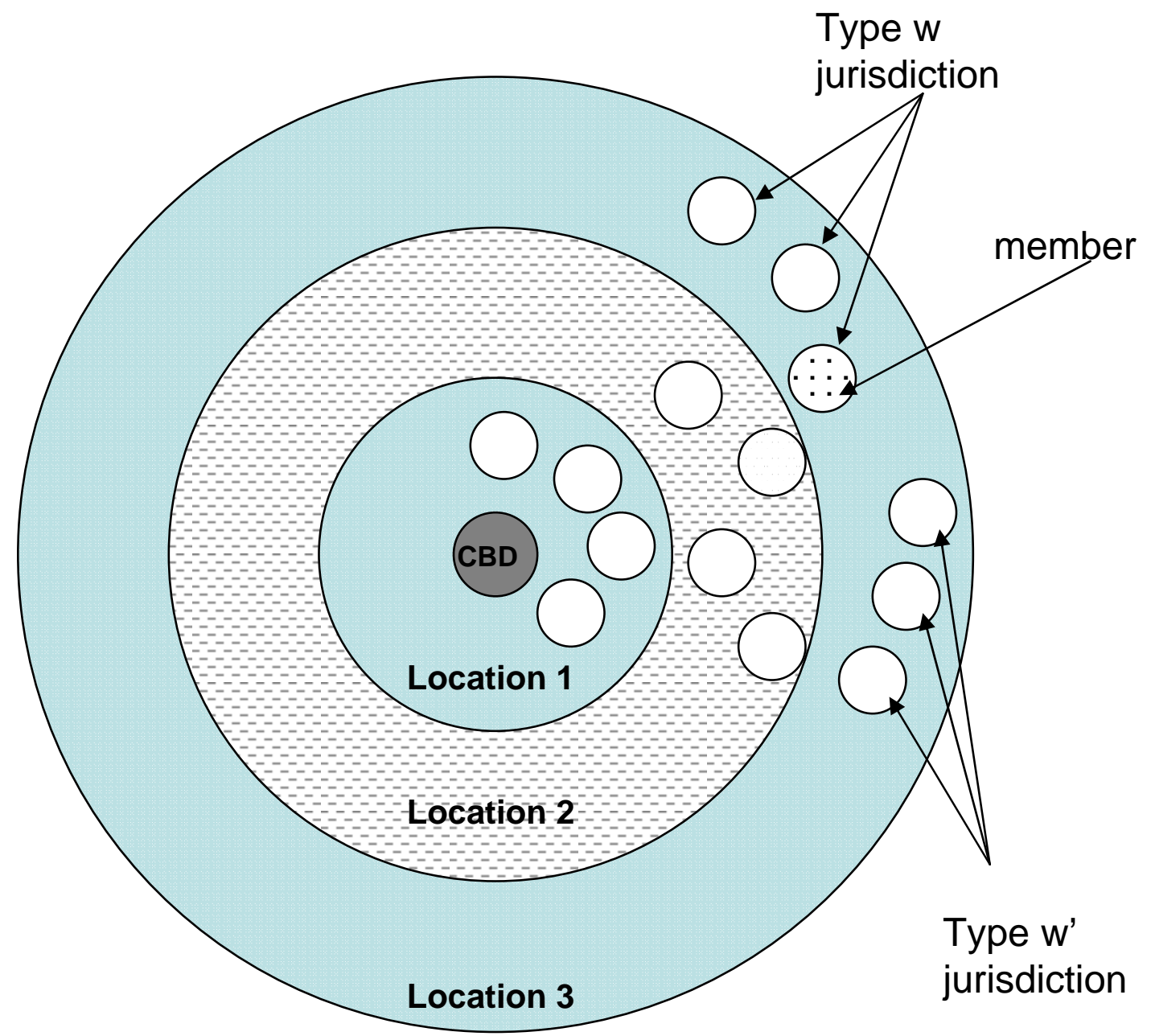

CBD: Central Business District

Figure 1

Urban Layout: Monocentric City Case 
actual existence of that type in equilibrium. ${ }^{10}$ That is, both consumers and jurisdictions know the prices of all possible jurisdiction types, and if we do not find a type of jurisdiction in equilibrium, then consumers are not interested in living in it and jurisdiction managers are not interested in creating it under its market price. ${ }^{11}$ This is certainly not a satisfactory assumption. Given price-taking consumers and jurisdiction managers, completeness of the price system is essential for the first welfare theorem to hold; however, we certainly do not observe all possible jurisdiction types in the real word. Without observing a type of jurisdiction in the economy, a price-taking jurisdiction manager cannot know the profitability (price) of such a jurisdiction type. Imagine the following example with only one observable jurisdiction type and price-taking jurisdiction managers: All jurisdictions adopted the same zero profit policy in an allocation. Jurisdiction managers are choosing the most profitable jurisdiction type among the ones they can observe (they are price-takers, so they can choose only from the observable types). Although consumers could have loved to move other types of jurisdictions, they have no choice but one type, thus they choose their optimal jurisdictions trivially. Thus, this is a price-taking equilibrium with an incomplete price system. ${ }^{12,13}$ It is easy to see that the same argument applies for many different subsets of jurisdiction types. Without the entrepreneurship of jurisdiction managers, a competitive equilibrium may not

\footnotetext{
${ }^{10}$ Sonstelie and Portney (1978) assume this explicitly as well. Although their equilibrium concepts are not defined formally, both Tiebout (1956) and Hamilton (1975) seem to assume the completeness of the market. The same remark applies to Scotchmer (1994) and Wildasin (1992). In hedonic price models that originated with Rosen (1974), it is also implicitly assumed that all possible goods (characteristics) are priced.

${ }^{11}$ This is "and" not "or." If one of the two condition is violated, there is excess supply or excess demand in the market, and the equilibrium condition is not met. In the example below, only the latter condition is satisfied (if there were such a jurisdiction, consumers would have been interested in it).

${ }^{12}$ This problem occurs in a classical general equilibrium model if there are potentially producible commodities which are originally nonexistent in the economy (endowments are zero for these commodities). For example, in hedonic price model (Rosen 1974), there is no reason for consumers and firms to know the "hedonic prices" of commodities that are not produced in the economy. The first welfare theorem can fail if the market is incomplete in our sense.

${ }^{13}$ Note that our "incomplete price system" is different from "incomplete market" in general equilibrium theory. If time and uncertainty are part of the model, the market can be incomplete even if all commodities have positive endowments and positive production levels (this latter one is the standard notion of incomplete market in general equilibrium theory: see, say, Magill and Shafer 1991).
} 
achieve efficiency.

In contrast, Wooders (1978) and Bewley (1981) consider equilibrium concepts in which prices are set only for existing jurisdiction types, and they assume that a group of consumers can form a coalitional deviation to create an unavailable type of jurisdiction (entrepreneurial consumers). However, allowing such a coalitional deviation of consumers does not fit very well with Tiebout's original tale: unlike Samuelson's pure public goods case, the market mechanism can achieve efficient allocations in equilibria even if jurisdictions cannot observe each consumer's preferences. ${ }^{14}$

In this paper, instead of assuming entrepreneurial consumers, we assume entrepreneurial jurisdiction managers. We will use a version of the well-known equilibrium concept defined for markets with asymmetric information (adverse selection) by Rothschild and Stiglitz (1976). ${ }^{15}$ We assume that a jurisdiction manager does not know each consumer's preference type (although she knows the distribution of their preference types), which is a more suitable assumption. An announced jurisdiction policy can attract only one type of consumer as resident if that type is the only one that derives higher utility from the policy than from currently available jurisdiction policies in the market. The equilibrium concept employed here requires that: (i) no consumer have an incentive to move among existing jurisdictions, and that (ii) there be no unavailable jurisdiction policy that can both attract consumers and be profitable to a jurisdiction manager. We call this Rothschild-Stiglitz type of equilibrium with zoning policies a Tiebout equilibrium with entrepreneurial jurisdictions. We will show that this equilibrium concept is indeed sufficient to prove the existence and efficiency of equilibrium.

\footnotetext{
${ }^{14}$ Recall the quote in the beginning of the paper. Another relevant quote is, ". . . Yet in terms of a satisfactory theory of public finance, it would be desirable (1) to force the voter to reveal his preferences; (2) to be able to satisfy them in the same sense that a private goods market does; and (3) to tax him accordingly." (Tiebout, 1956, pp. 417-418.)

${ }^{15}$ In Rothschild and Stiglitz (1976), there are low-risk and high-risk consumers, and insurance companies compete with each other via their insurance plans in a competitive market (with free entry). Insurance companies cannot distinguish consumer types, although they know the distribution of consumer types. They show that equilibrium may fail to exist: when high-risks and low-risks choose the same plan an insurance firm has an incentive to offer a plan that attracts only low-risks, whereas when two types choose different plans by self-selection, there may be a plan that attracts both.
} 


\section{The Mechanism of Achieving Efficiency}

In this section, we show how Hamilton (1975), together with Rothschild and Stiglitz (1976), supports Tiebout's tale (1956). Hamilton's zoning policy recovers (existence and) efficiency of equilibrium under a property tax system in two different ways: one is by supporting an efficient allocation by (distortionary) property taxes, and the other by preserving fiscal anonymity of crowding in order to avoid the free-rider problem. First, Figure 2 shows that property tax is distortionary unless a zoning policy is in place: point $A$ is an efficient equilibrium while point $B$ is the inefficient one. If zoning policies are not in place, all consumers want to reduce their land consumption (point $B$ ). Note that if a zoning policy is not binding, then entrepreneurial jurisdictions that put in place zoning policies that are binding can make profits by removing distortions. Hamilton's zoning policy is essential in recovering efficiency of a Tiebout equilibrium by eliminating distortions. ${ }^{16}$

\section{[Figure 2.]}

Second, and more important, a zoning policy also works as a tool that prevents free-rider problems. Suppose that rich people strongly prefer large land lots, while the poor prefer small lots if land is expensive. Then, if they live in the same jurisdiction, the rich will need to pay a lot in property taxes, while the poor can enjoy local public goods for much less in property taxes. Thus, without zoning policies, a resident's utility depends on the composition of the population of her jurisdiction: i.e., congestion is not fiscally anonymous due to property taxes. Pauly (1976) describes this problem as a "poor chasing the rich" situation. Structurally this is exactly the problem faced by the insurance market in Rothschild and Stiglitz (1976). High-risk and low-risk consumers correspond to the poor and the rich in our model, respectively. As is well known in the literature, neither existence nor efficiency is guaranteed in insurance markets with the Rothschild-Stiglitz equilibrium (Rothschild and Stiglitz 1976). However, Hamilton's zoning policy makes tax payments equal in the same jurisdiction (if the constraint binds), and congestion becomes anonymous in our local public goods economy. ${ }^{17}$ This is because zoning policy makes congestion under property tax fiscally anonymous (since every household in the

\footnotetext{
${ }^{16}$ See Wheaton (1975). Wheaton (1975) says that Tiebout's efficiency tale is incorrect since property taxes are distortionary.

${ }^{17}$ The Rothschild-Stiglitz equilibrium can be used for Rosen's hedonic price models in the same way without assuming a complete price system for all potential commodities.
} 


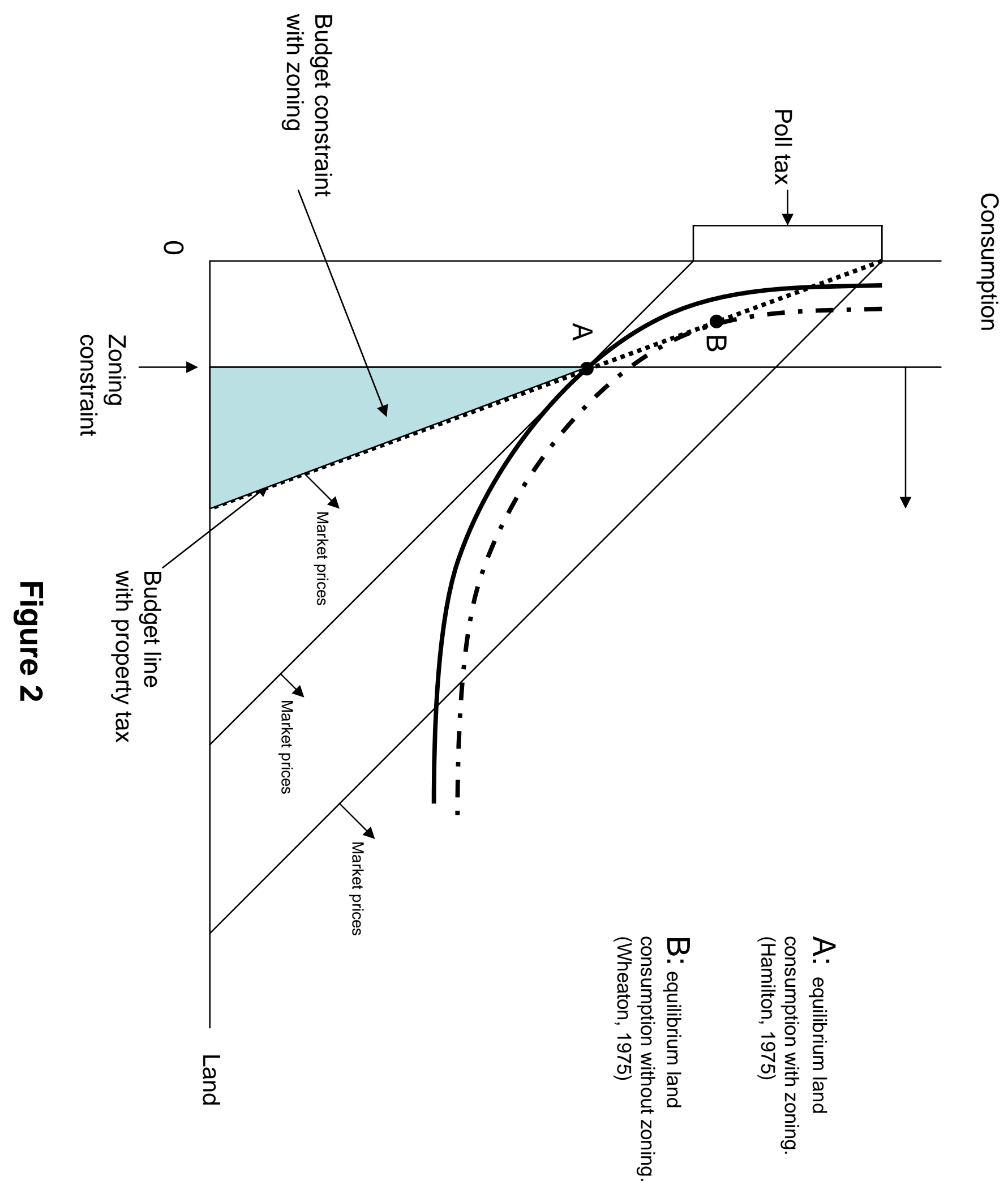


same jurisdiction needs to pay the same amount under the policy). This implies that cost of a public project in the jurisdiction is divided equally, and a property tax becomes essentially a poll tax. ${ }^{18}$

With this observation, our efficiency result can be easily shown. First, assuming all types of jurisdictions (in public projects and the population), we find a competitive equilibrium with poll taxes by letting each type of consumer choose her most favorite jurisdiction type among all budget-balancing jurisdiction types. We can show that this poll tax equilibrium is Pareto efficient by employing McKenzie's trading set approach (McKenzie 1959). Then, we can achieve our goal if we can prove that a Tiebout equilibrium with entrepreneurial jurisdictions is equivalent to the poll tax equilibrium. By our observation (Figure 1), it is easy to see that every poll tax equilibrium can be supported by a Tiebout equilibrium with entrepreneurial jurisdictions (a Rothschild-Stiglitz equilibrium with property taxes and zoning policies). The other direction is to show that every Tiebout equilibrium with entrepreneurial jurisdictions is a poll tax equilibrium. Here, condition (ii) of the equilibrium (of Rothschild and Stiglitz 1976) plays an important role: there must be no unavailable jurisdiction policy that can both attract consumers and be profitable to a jurisdiction manager. This is a free entry condition, and if an allocation is inefficient, an entrepreneurial jurisdiction manager can make profits by offering a policy package to a particular type of consumer that is better than the packages currently available in the market. ${ }^{19}$ This shows that every Tiebout equilibrium with entrepreneurial jurisdictions must be an allocation in which each type is totally segregated and achieves the maximum payoff under segregations. This is a poll tax equilibrium. This is why we can derive the first welfare theorem for a Tiebout equilibrium with entrepreneurial jurisdictions.

In the rest of the paper, we formally define Tiebout equilibrium with entrepreneurial jurisdictions, and prove the existence and efficiency of the equi-

\footnotetext{
${ }^{18}$ Nechyba (1997) analyzes a local public good model with existing houses (thus, consumers can choose only from existing house/lot sizes). His setup resembles Hamilton's (binding) zoning policies. The difference is that since new houses cannot be provided by jurisdiction managers in Nechyba's case, the global Pareo efficient allocation cannot be achieved.

${ }^{19}$ Indeed, in a Tiebout economy, Brueckner (1981) shows by an example that there may be inefficient equilibria other than the efficient sorting equilibrium unless free entry of jurisdictions is assumed. Brueckner (1981) assumes a perfectly elastic land supply, which turns out to be consistent with our infinitesimal jurisdiction assumption in the current paper. Bewley (1981) also stresses the importance of free entry.
} 
librium.

\section{The Model}

The model assumes that there are finitely many physical locations in the economy. The set of locations is denoted $J$, and its representative element is $j \in J$. These locations can differ in climate or in geographical features. Each location $j$ has some quantity of land $L_{j}>0$, i.e., each location has only a limited amount of land to utilize. There is one numeraire commodity which can be produced by labor at each location $j \in J$ with constant-returns-to-scale location-specific technology: that is, the amount of labor needed to produce one unit of the numeraire commodity at location $j \in J$ is constant and is denoted $\alpha_{j}$, which can be dependent on $j$. At location $j \in J$, the prices of privately consumed goods - the numeraire commodity, land, and leisure are $1, r_{j}$, and $w_{j}$, respectively. Given the constant returns to scale technology, $w_{j} \alpha_{j}=1$. There is a finite number of possible public projects (see Mas-Colell, 1980). Public projects are discrete public goods such as schools, parks, and water supply systems, etc., and any combinations of them. The set of all public projects is denoted $G$, and its representative element is $g \in G$. Each public project $g \in G$ can be produced by $c(g)$ units of the numeraire commodity. We assume that provision of no public project is always available for jurisdiction managers: $\emptyset \in G$ with $c(\emptyset)=0$ (no provision, so no cost).

A type $\omega$ jurisdiction provides a public project and imposes a land tax (property tax) on its residents. Each jurisdiction $\omega$ is characterized by its location $j_{\omega} \in J$, public project $g_{\omega} \in G$, total land size $L_{\omega}$, and (specific) land $\operatorname{tax} t_{\omega}$. In addition, jurisdictions can impose zoning constraints (Hamilton 1975): i.e., the size of the lot for each household must be greater than or equal to $\zeta_{\omega}: z \geq \zeta_{\omega}$ (if no zoning constraint, $\zeta_{\omega}=0$ ). Although zoning constraints are inequalities, in the equilibrium they will be binding, as we will see below (proof of Proposition 3; see also Figure 1). Thus, we will impose zoning constraints as equalities for brevity of explanation: that is, a resident of type $\omega$ jurisdiction must consume $\zeta_{\omega}$ land. The total land size $L_{\omega}$ is determined by how many residents join the jurisdiction, and $L_{\omega}=\zeta_{\omega} n_{\omega}$ follows under zoning requirement $\zeta_{\omega}$, where $n_{\omega}$ is the number of households in a type $\omega$ jurisdiction. Thus, a type $\omega$ jurisdiction is characterized by its policy list $\omega=\left(j_{\omega}, g_{\omega}, t_{\omega}, \zeta_{\omega}, n_{\omega}\right)$. The set of all possible policy lists is denoted $\Omega=$ $J \times G \times \mathbb{R}_{+} \times \mathbb{R}_{+} \times \mathbb{Z}_{++}$, where $\mathbb{Z}_{++}$is the set of positive integers. 
There is a finite number of types of consumers. The set of all types is denoted $\Theta$, and its representative element is $\theta \in \Theta$. A type $\theta$ consumer has a location-specific utility function $u_{j}^{\theta}: \mathbb{R}_{+} \times\left[0, \bar{\ell}_{j}^{\theta}\right] \times \mathbb{R}_{+} \times G \times \mathbb{Z}_{++} \rightarrow \mathbb{R}$ for each $j \in J$ such that $u_{j}^{\theta}(x, \ell, z, g, n)$ denotes type $\theta$ 's utility who lives in a jurisdiction at location $j$ that provides public project $g$ with $n$ residents, consuming numeraire, land, and leisure by $x, z$, and $\ell$. We assume that there is no spillover benefit of local public goods across jurisdiction borders. Without this assumption, it is obvious that equilibrium efficiency is not attained without internalizing such externalities. Type $\theta$ consumer can spend at most $\bar{\ell}_{j}^{\theta}$ leisure hours at location $j$, where $\bar{\ell}_{j}^{\theta}>0$ denotes type $\theta$ 's leisure endowment hours at location $j \in J .{ }^{20}$ We assume that $u_{j}^{\theta}$ is a continuous function. Type $\theta$ consumer is endowed with land vector $\left(\bar{L}_{j}^{\theta}\right)_{j \in J} \in \mathbb{R}_{+}^{J}$. That is, a consumer's utility depends on private goods consumption $x, z$, and $\ell$, public project $g$, and the level of congestion $n$ as well as her choice of location $j$ itself. However, under the provision of no public projects, $g=\emptyset$, congestion is assumed to be irrelevant: $u_{j}^{\theta}(x, \ell, z, \emptyset, n)=u_{j}^{\theta}\left(x, \ell, z, \emptyset, n^{\prime}\right)$ for all $n, n^{\prime} \in \mathbb{Z}_{++}$, and all $(x, \ell, z) \in \mathbb{R}_{+} \times\left[0, \bar{\ell}_{j}^{\theta}\right] \times \mathbb{R}_{+}$. Note that we assume that the physical crowding effect in public projects is anonymous; it does not depend on whom one shares a public project with if cost share is not in consideration. ${ }^{21}$ In a jurisdiction $\omega$ at location $j$, type $\theta$ 's budget constraint is denoted

$$
x+\left(r_{j}+t_{\omega}\right) \zeta_{\omega} \leq w_{j}\left(\bar{\ell}_{j_{\omega}}^{\theta}-\ell\right)+\sum r_{j} \bar{L}_{j}^{\theta}
$$

where $L=\zeta_{\omega}$ if $\omega$ has a zoning restriction. Thus, type $\theta$ 's utility from choosing jurisdiction $\omega$ is

$$
\begin{gathered}
U^{\theta}\left(\omega ;\left(w_{j}, r_{j}\right)_{j \in J}\right) \equiv \max _{x, \ell, z} u_{j_{\omega}}^{\theta}\left(x, \ell, z, g_{\omega}, n_{\omega}\right) \\
\text { subject to } \quad x+\left(r_{j_{\omega}}+t_{\omega}\right) z \leq w_{j_{\omega}}\left(\bar{\ell}_{j_{\omega}}^{\theta}-\ell\right)+\sum r_{j} \bar{L}_{j}^{\theta} \text { and } z \geq \zeta_{\omega}
\end{gathered}
$$

and thus, type $\theta$ 's jurisdiction choice correspondence is

$$
\omega^{*}(\theta) \equiv \arg \max _{\omega \in \Omega^{*}} U^{\theta}(\omega)
$$

\footnotetext{
${ }^{20}$ We allow leisure endowment hours to be dependent on a consumer's choice of residential location. This is so we can describe minutes spent in commuting as dependent on her choice of location.

${ }^{21}$ However, if tax payment is linked with lot sizes (property tax), then depending on income and/or preferences, congestion becomes fiscally nonanonymous without Hamilton's zoning policy.
} 
where $\Omega^{*}$ denotes the set of available jurisdiction types. Each jurisdiction has a manager who maximizes its fiscal surplus, $t_{\omega} \zeta_{\omega} n_{\omega}-c\left(g_{\omega}\right)$ (tax revenue minus expenditure) by choosing a policy $\left(j_{\omega}, g_{\omega}, t_{\omega}, \zeta_{\omega}, n_{\omega}\right)$. The manager knows the consumers' utility functions and other jurisdictions' policy choices, and chooses a profit-maximizing policy that is meant to attract consumers (for its residents, that jurisdiction policy gives the highest payoffs). This setup allows a jurisdiction manager to attract potential residents to her jurisdiction in order to raise fiscal surplus, instead of taking her resident profile as given.

We impose a few key assumptions on the populations of individuals and jurisdiction memberships. These are adopted from the papers that prove the existence and efficiency of equilibrium in nonspatial settings: Ellickson et al. (1999), and Allouch et al. (2004).

Integer Populations within Jurisdictions (IP). The number of members of a jurisdiction must be integer-valued.

Large Population (LP). There is a continuum of consumers. The measure (population) of type $\theta$ consumer is denoted $m^{\theta}>0$ and $\sum_{\theta \in \Theta} m^{\theta}=1$.

Finitely Populated Jurisdictions (FP). Each jurisdiction can have only a finite number of residents, and the number is bounded from above. That is, $n_{\omega} \leq \bar{n}$

Measurement Consistency (MC). Suppose that there are Lebesgue measure $\mu^{\prime}$ of jurisdictions that have the same population composition $\left(n_{\theta}\right)_{\theta \in \Theta} \in$ $\mathbb{Z}_{+}^{|\Theta|}$ (i.e., $n_{\theta}$ is the number of type $\theta$ consumers in each jurisdiction) in the economy. Then, the total population of type $\theta$ consumers who belong to those jurisdictions is $\mu^{\prime} \times n_{\theta}$ for all $\theta \in \Theta$.

Assumption IP, which was already introduced above in our definition of utility functions, is standard in the literature on local public goods economies with an endogenous number of jurisdictions. Assumption LP is also standard in order to avoid integer problems that result in nonexistence of equilibrium. Assumption FP is key for our result. Assuming finiteness of residents in each jurisdiction together with a continuum of consumers (and finite types) guarantees the dissolution of integer problems. Note that FP together with LP necessarily implies that there is a continuum of jurisdictions in the economy 
(Ellickson et al. 1999, and Allouch et al. 2004). Bewley (1981) made many critical comments on Tiebout's tale, but his negative results are partly the result of his not adopting IP and FP: Bewley assumed that there is a finite number of jurisdictions, while LP implies that there is a continuum of consumers in jurisdictions. FP has been formulated in various ways with various labels. However, the simplest way to state it (for our purposes) is as above. Wooders (1980) was the first to introduce this assumption in a large finite economy. Kaneko and Wooders (1986) extended it in a continuum economy in order to dismiss a small-scale integer problem. The last assumption MC is a technical assumption in a continuum economy. It requires that the composition of a finite population aggregate nicely to a composition of a continuum of population, which is also introduced by Kaneko and Wooders (1986). We use this assumption in the proof of propositions in order to aggregate consumers' jurisdiction and consumption choices. We assume IP, LP, FP, and $\mathrm{MC}$ throughout the paper.

The equilibrium is described as follows. Since there will be a continuum of jurisdictions that use the same policies, we use $\omega$ to represent the policy of a jurisdiction $\left(j_{\omega}, g_{\omega}, t_{\omega}, \zeta_{\omega}, n_{\omega}\right)$ instead of a jurisdiction itself (there will be many jurisdictions that use the same policies). That is, we set $\omega=\left(j_{\omega}, g_{\omega}, t_{\omega}, \zeta_{\omega}, n_{\omega}\right)$, and $\Omega$ is the set of available policies.

Definition. A Tiebout equilibrium with entrepreneurial jurisdictions is a list of $\left(\left(r_{j}^{*}, w_{j}^{*}\right)_{j \in J}, \Omega^{*},\left(j_{\omega}, g_{\omega}, t_{\omega}, \zeta_{\omega}, n_{\omega}\right)_{\omega \in \Omega^{*}},\left(m_{\omega}^{\theta}, x_{\omega}^{\theta}, \ell_{\omega}^{\theta}\right)_{\theta \in \Theta, \omega \in \Omega^{*}}\right)$ with $\sum_{\omega \in \Omega} m_{\omega}^{\theta}=m^{\theta}$ for all $\theta \in \Theta$ such that

1. (Optimality of Private Consumption Choice)

For all $\omega \in \Omega^{*}$, and all $\theta \in \Theta$ with $m_{\omega}^{\theta}>0,\left(x_{\omega}^{\theta}, \ell_{\omega}^{\theta}, \zeta_{\omega}\right) \in \arg \max _{x, \ell} u_{j_{\omega}}^{\theta}\left(x, \ell, z, g_{\omega}, n_{\omega}\right)$ s.t. $\quad x+\left(r_{j_{\omega}}^{*}+t_{\omega}\right) z \leq w_{j_{\omega}}^{*}\left(\bar{\ell}_{j}^{\theta}-\ell\right)+\sum r_{j}^{*} \bar{L}_{j}^{\theta}$ and $z \geq \zeta_{\omega}$

2. (Optimality of Jurisdiction Choice)

For all $\omega \in \Omega^{*}$, and all $\theta \in \Theta$ with $m_{\omega}^{\theta}>0$, we have $\omega \in \arg \max _{\omega^{\prime} \in \Omega^{*}} U^{\theta}\left(\omega^{\prime} ;\left(w_{j}^{*}, r_{j}^{*}\right)_{j \in J}\right)$

3. (Land Market Clearing)

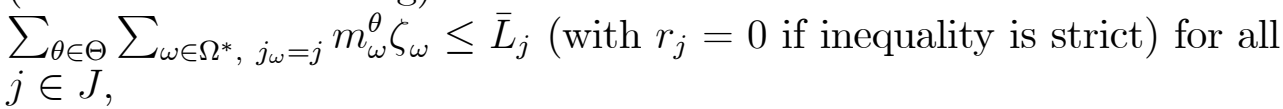

4. (Profit Maximization) $w_{j}^{*}=\frac{1}{\alpha_{j}}$ for all $j \in J$ 
5. (Numeraire Commodity Market Clearing)

$\sum_{\theta \in \Theta} \sum_{\omega \in \Omega^{*}, j_{\omega}=j} m_{\omega}^{\theta} \alpha_{j}\left(\bar{\ell}_{\omega}^{\theta}-\ell_{\omega}^{\theta}\right)=\sum_{\theta \in \Theta} \sum_{\omega \in \Omega^{*}} m_{\omega}^{\theta} x_{\omega}^{\theta}+\sum_{\omega \in \Omega^{*}}\left(\sum_{\theta \in \Theta} m_{\omega}^{\theta}\right) \frac{c\left(g_{\omega}\right)}{n_{\omega}}$

6. (Jurisdiction's Zero Profit Condition)

$t_{\omega} \zeta_{\omega} n_{\omega}=c\left(g_{\omega}\right)$ for all $\omega \in \Omega^{*}$

7. (Exhausted Profit Opportunities by Entrepreneurial Jurisdictions)

For all $\omega \in \Omega \backslash \Omega^{*}$ with $t_{\omega} \zeta_{\omega} n_{\omega}>c\left(g_{\omega}\right)$, we have for all $\theta \in \Theta$,

$$
\begin{aligned}
& \max _{\omega^{\prime} \in \Omega^{*}} U^{\theta}\left(\omega^{\prime}\right) \\
> & \max _{x, \ell} u_{j_{\omega}}^{\theta}\left(x, \ell, \zeta_{\omega}, g_{\omega}, n_{\omega}\right) \quad \text { s.t. } \quad x+\left(r_{j_{\omega}}^{*}+t_{\omega}\right) \zeta_{\omega} \leq w_{j_{\omega}}^{*}\left(\bar{\ell}_{j_{\omega}}^{\theta}-\ell\right)+\sum_{j \in J} r_{j}^{*} \bar{L}_{j}^{\theta} .
\end{aligned}
$$

The key to the above definition is that we distinguish between $\Omega^{*}$ (observed jurisdiction policies) and $\Omega \backslash \Omega^{*}$ (unobserved jurisdiction policies). Jurisdiction managers can easily observe how profitable a policy is as long as there is a jurisdiction that chooses that policy. However, if a policy is not chosen by any jurisdiction, the managers need to estimate how profitable it would be by utilizing her information on consumers' utilities (in the manner of Rothschild and Stiglitz, 1976). This entrepreneurship is captured in equilibrium condition 7. In contrast, if managers are passive, there can be many inefficient equilibria if no jurisdiction chooses potentially profitable policies that go unobserved. As we discussed in the introduction, our equilibrium concept differs from those of Ellickson et al. (1999) and Allouch et al. (2004). We assume that there is no market for unobserved policies $\left(\omega \in \Omega \backslash \Omega^{*}\right)$. Our condition 7 is similar to a condition in the equilibrium concept of Rothschild and Stiglitz (1976), and it preserves efficiency of equilibrium through entrepreneurship by jurisdiction managers. Wooders (1978) and Bewley (1981) have similar ideas, but instead of exhausting the possible policies proposable by jurisdiction managers, they consider a coalitional deviation constructed by a group of consumers. The main difference is that coalitional deviations are initiated by consumers, whereas profit opportunities are sought by jurisdiction managers who have information on the distribution of consumers' preference types.

Remark 1. There is one additional issue related to condition 7 . This is a coordination problem among consumers. Even if a jurisdiction manager announces a policy that attracts some type profitably, that is, even if she 
announces $\omega=\left(j_{\omega}, g_{\omega}, t_{\omega}, \zeta_{\omega}, n_{\omega}\right) \notin \Omega^{*}$ with $t_{\omega} \zeta_{\omega} n_{\omega}>c\left(g_{\omega}\right)$ such that for some $\theta \in \Theta$,

$$
\begin{aligned}
& \max _{\omega^{\prime} \in \Omega^{*}} U^{\theta}\left(\omega^{\prime}\right) \\
< & \max _{x, \ell} u_{j_{\omega}}^{\theta}\left(x, \ell, \zeta_{\omega}, g_{\omega}, n_{\omega}\right) \quad \text { s.t. } \quad x+\left(r_{j_{\omega}}^{*}+t_{\omega}\right) \zeta_{\omega} \leq w_{j_{\omega}}^{*}\left(\bar{\ell}_{j}^{\theta}-\ell\right)+\sum_{j \in J} r_{j}^{*} \bar{L}_{j}^{\theta}
\end{aligned}
$$

holds, a coordination problem may still arise. This problem occurs if consumers do not like to have vacant houses in a jurisdiction. That is, if for all such $\omega \notin \Omega^{*}$, there is $n<n_{\omega}$ (namely $n=1$ ) such that for all $\theta \in \Theta$,

$$
\begin{aligned}
& \max _{\omega^{\prime} \in \Omega^{*}} U^{\theta}\left(\omega^{\prime}\right) \\
> & \max _{x, \ell} u_{j_{\omega}}^{\theta}\left(x, \ell, \zeta_{\omega}, g_{\omega}, n\right) \quad \text { s.t. } \quad x+\left(r_{j_{\omega}}^{*}+t_{\omega}\right) \zeta_{\omega} \leq w_{j_{\omega}}^{*}\left(\bar{\ell}_{j}^{\theta}-\ell\right)+\sum_{j \in J} r_{j}^{*} \bar{L}_{j}^{\theta}
\end{aligned}
$$

holds, then a pessimistic manager may have troubles in filling the new jurisdiction with consumers. Consumers may believe that the jurisdiction would never filled, and that they could be worse off if they move in. If this is the case, jurisdiction managers cannot feel safe to announce $\omega$, although if type $\theta$ consumers would fill all vacancies, then both the consumers and the jurisdiction manager would be strictly better off. ${ }^{22}$ If such pessimism by consumers and jurisdiction managers were allowed, condition 7 should be modified as follows:

7'. For all $\omega \in \Omega \backslash \Omega^{*}$ with $t_{\omega} \zeta_{\omega} n_{\omega}>c\left(g_{\omega}\right)$, we have for all $\theta \in \Theta$, there exists $n \in\left\{1, \ldots, n_{\omega}\right\}$ such that the above $(* *)$ holds.

However, then, our equilibrium concept would support inefficient allocations. The following negative population externalities assumption eliminates such pessimism, and guarantees the efficiency of the Tiebout equilibrium with entrepreneurial jurisdictions. A simple way to avoid this coordination problem is to assume negative population externalities (NPE):

NPE. For all $(\theta, j, g) \in \Theta \times J \times G$, all $(x, \ell, z) \in \mathbb{R}_{++} \times\left[0, \bar{\ell}_{j}^{\theta}\right] \times \mathbb{R}_{+}$and all $n, n^{\prime} \in \mathbb{Z}_{++}$with $n<n^{\prime}$, we have

$$
u_{j}^{\theta}(x, \ell, z, g, n) \geq u_{j}^{\theta}\left(x, \ell, z, g, n^{\prime}\right) .
$$

\footnotetext{
${ }^{22}$ I thank Atsushi Kajii and one of the referees for raising this issue.
} 
This condition is commonly assumed in local public goods economies, and asserts that consumers weakly prefer less crowded jurisdiction if all other things are equal. It assures that condition $7^{\prime}$ and NPE together imply condition 7 of the Tiebout equilibrium with entrepreneurial jurisdictions, since the above coordination problem disappears.

The main result is stated below.

Theorem. There exists a Tiebout equilibrium with entrepreneurial jurisdictions, and it is Pareto efficient under the following assumptions about utility functions:

1. For all $\theta \in \Theta$, all $j \in J$, all $g \in G$, all $n \in N=\{1, \ldots, \bar{n}\},, u_{j}^{\theta}(x, \ell, L, g, n)$ is continuous and strictly monotonic in $(x, \ell, L)$,

2. for all $\theta \in \Theta$, all $j \in J$, all $\ell_{j} \in\left[0, \bar{\ell}_{j}^{\theta}\right]$, all $L \in \mathbb{R}_{+}$, all $g \in G$, all $n \in$ $N=\{1, \ldots, \bar{n}\}, u_{j}^{\theta}(0, \ell, L, g, n)=\underline{u}^{\theta} \equiv \min _{\left(j^{\prime}, x^{\prime}, \ell^{\prime}, L^{\prime}, g^{\prime}, n^{\prime}\right)} u_{j^{\prime}}^{\theta}\left(0, \ell^{\prime}, L^{\prime}, g^{\prime}, n^{\prime}\right)$ (essentiality of numeraire), ${ }^{23}$

3. for all $\theta \in \Theta$, all $j \in J$, all $g \in G$, and all $n \in N=\{1, \ldots, \bar{n}\}$, $u_{j}^{\theta}(x, \ell, L, g, n)$ is strictly quasi-concave in $(x, \ell, L)$.

\section{Sketch of the Proof}

The formal proof is delegated to the appendix; here we give a sketch of the proof and remark on some of its key arguments. We prove the theorem with four propositions. We first define "Tiebout equilibrium with poll taxes" and show that it exists and is efficient (Propositions 1 and 2). Then we show that this equilibrium is essentially equivalent to a Tiebout equilibrium with entrepreneurial jurisdictions (Propositions 3 and 4).

With poll taxes, the definition of a policy is different. Let each jurisdiction charge a poll tax $\tau=c(g) / n$ for a policy $\tilde{\omega}=\left(j_{\tilde{\omega}}, g_{\tilde{\omega}}, \tau_{\tilde{\omega}}, n_{\tilde{\omega}}\right) \in \tilde{\Omega}=$ $J \times G \times \mathbb{R}_{+} \times\{1, \ldots, \bar{n}\}$. Besides this, a Tiebout equilibrium with poll taxes still differ from a Tiebout equilibrium with entrepreneurial jurisdictions in

\footnotetext{
${ }^{23}$ See Mas-Colell (1977), Wooders (1978), and Ellickson (1979) for the spirit of this assumption.
} 
two ways. First, jurisdictions' tax policies are poll taxes instead of property taxes. Second, we assume a complete price system (there are prices for all $\tilde{\omega} \in \tilde{\Omega}$ ) and no zoning restrictions. Our proof of the theorem is indirect: We analyze the properties of an equilibrium with poll taxes, and show that the equilibrium allocations are essentially equivalent between these two equilibrium concepts. A Tiebout equilibrium with poll taxes is easier to deal with. Note that the jurisdiction policy space is now different $(\tilde{\Omega}$ instead of $\Omega$ : $\left.\omega=\left(j_{\omega}, g_{\omega}, t_{\omega}, \zeta_{\omega}, n_{\omega}\right) \in \Omega\right)$.

Definition. A Tiebout equilibrium with poll taxes is a list of $\left(\left(r_{j}^{*}, w_{j}^{*}\right)_{j \in J},\left(j_{\tilde{\omega}}, g_{\tilde{\omega}}, \tau_{\tilde{\omega}}, n_{\tilde{\omega}}\right)_{\tilde{\omega} \in \tilde{\Omega}},\left(m_{\tilde{\omega}}^{\theta}, x_{\tilde{\omega}}^{\theta}, \ell_{\tilde{\omega}}^{\theta}, z_{\tilde{\omega}}^{\theta}\right)_{\theta \in \Theta, \tilde{\omega} \in \tilde{\Omega}}\right)$ with $\sum_{\tilde{\omega} \in \tilde{\Omega}} m_{\tilde{\omega}}^{\theta}=m^{\theta}$ for all $\theta \in \Theta$ such that

1. (Optimality of Private Consumption Choice)

For all $\tilde{\omega} \in \tilde{\Omega}$, and all $\theta \in \Theta,{ }^{24}\left(x_{\tilde{\omega}}^{\theta}, \ell_{\tilde{\omega}}^{\theta}, z_{\tilde{\omega}}^{\theta}\right) \in \arg \max _{x, \ell, z} u_{j_{\tilde{\omega}}}^{\theta}\left(x, \ell, z, g_{\tilde{\omega}}, n_{\tilde{\omega}}\right)$ s.t. $\quad x+r_{j_{\tilde{\omega}}}^{*} z+\tau_{\tilde{\omega}} \leq w_{j_{\tilde{\omega}}}^{*}\left(\bar{\ell}_{j_{\tilde{\omega}}}^{\theta}-\ell\right)+\sum r_{j}^{*} \bar{L}_{j}^{\theta}$, and if the budget set is empty for $\theta$, assign $(0,0,0) .{ }^{25}$

2. (Optimality of Jurisdiction Choice)

For all $\tilde{\omega} \in \tilde{\Omega}$, and all $\theta \in \Theta$ with $m_{\tilde{\omega}}^{\theta}>0$, we have

$\tilde{\omega} \in \arg \max _{\tilde{\omega}^{\prime} \in \tilde{\Omega}} \tilde{U}^{\theta}\left(\tilde{\omega}^{\prime} ;\left(r_{j}^{*}, w_{j}^{*}\right)_{j \in J}\right)=u_{j_{\tilde{\omega}}}^{\theta}\left(x_{\tilde{\omega}}^{\theta}, \ell_{\tilde{\omega}}^{\theta}, z_{\tilde{\omega}}^{\theta}, g_{\tilde{\omega}}, n_{\tilde{\omega}}\right)$

3. (Land Market Clearing)

$\sum_{\theta \in \Theta} \sum_{\tilde{\omega} \in \tilde{\Omega}, j_{\tilde{\omega}=j}} m_{\tilde{\omega}}^{\theta} z_{\tilde{\omega}} \leq \bar{L}_{j}$ (with $r_{j}=0$ if inequality is strict) for all $j \in J$

4. (Profit Maximization)

$w_{j}^{*}=\frac{1}{\alpha_{j}}$ for all $j \in J$

5. (Numeraire Commodity Market Clearing)

$\sum_{\theta \in \Theta} \sum_{\tilde{\omega} \in \tilde{\Omega}, j_{\tilde{\omega}}=j} m_{\tilde{\omega}}^{\theta} \alpha_{j}\left(\bar{\ell}_{\tilde{\omega}}^{\theta}-\ell_{\tilde{\omega}}^{\theta}\right)=\sum_{\theta \in \Theta} \sum_{\tilde{\omega} \in \tilde{\Omega}} m_{\tilde{\omega}}^{\theta} x_{\tilde{\omega}}^{\theta}+\sum_{\tilde{\omega} \in \tilde{\Omega}}\left(\sum_{\theta \in \Theta} m_{\tilde{\omega}}^{\theta}\right) \frac{c\left(g_{\tilde{\omega}}\right)}{n_{\tilde{\omega}}}$

\footnotetext{
${ }^{24}$ Note that not all types live in type $\tilde{\omega}$ jurisdictions. For some type $\theta, m_{\tilde{\omega}}^{\theta}=0$ may be the case. For such a type, $\left(x_{\tilde{\omega}}^{\theta}, \ell_{\tilde{\omega}}^{\theta}, z_{\tilde{\omega}}^{\theta}\right)$ is irrelevant information. However, for convenience, we include these consumers' optimal choices in the definition of equilibrium.

${ }^{25}$ This is just for technical convenience (type $\theta$ consumers at $\tilde{\omega}$ has a zero measure). Under assumption 2 in the theorem, $(0,0,0)$ would not be a consumer's choice (see the proof of Proposition 1). Also, we assign $\left(x_{\tilde{\omega}}^{\theta}, \ell_{\tilde{\omega}}^{\theta}, z_{\tilde{\omega}}^{\theta}\right)$ to type $\theta$ consumer at $\tilde{\omega}$ as long as the budget set is nonempty even if $m_{\tilde{\omega}}^{\theta}=0$. This is just for the purpose of obtaining a well-defined and well-behaved fixed point mapping.
} 


\section{6. (Jurisdiction's Zero Profit Condition) $\tau_{\tilde{\omega}} n_{\tilde{\omega}}=c\left(g_{\tilde{\omega}}\right)$ for all $\tilde{\omega} \in \tilde{\Omega}$.}

Assuming a complete price system, that is, assuming there are prices for all possible $\tilde{\omega} \mathrm{s}$, we can find an equilibrium. ${ }^{26}$

Proposition 1. There exists a Tiebout equilibrium with poll taxes under the following assumptions:

1. For all $\theta \in \Theta$, all $j \in J$, all $g \in G$, all $n \in N=\{1, \ldots, \bar{n}\},, u_{j}^{\theta}(x, \ell, L, g, n)$ is continuous and strictly monotonic in $(x, \ell, L)$;

2. For all $\theta \in \Theta$, all $j \in J$, all $\ell_{j} \in\left[0, \bar{\ell}_{j}^{\theta}\right]$, all $L \in \mathbb{R}_{+}$, all $g \in G$, all $n \in\{1, \ldots, \bar{n}\}, u_{j}^{\theta}(0, \ell, L, g, n)=\underline{u}^{\theta}$ (essentiality of numeraire); and

3. For all $\theta \in \Theta$, all $j \in J$, all $g \in G$, and all $n=N \in\{1, \ldots, \bar{n}\}$, $u_{j}^{\theta}(x, \ell, L, g, n)$ is strictly quasi-concave in $(x, \ell, L)$.

The proof of Proposition 1 is basically along the lines of Ellickson et al. (1999), although ours is less technically involved since we use the distribution approach (see Hart, Hildenbrand, and Kohlberg 1974) and assume strictly quasi-concave utility. However, adding spatiality to the model complicates the problem. First of all, we need to formalize the consumption sets of consumers. The difficulty is that each consumer's leisure (labor) endowment/consumption and land consumption are dependent on and restricted by her location choice. That is, if a consumer chooses a type $\tilde{\omega}$ jurisdiction at location $j_{\tilde{\omega}} \in J$, her leisure endowment and her leisure and land consumption must be at location $j_{\tilde{\omega}}$. In contrast, land endowment is not affected by location choice. Further, $g_{\tilde{\omega}} \in G$ and $n_{\tilde{\omega}} \in\{1, \ldots, \bar{n}\}$ can affect consumers' choices over private goods consumption. Under a complete market system, each consumer can choose any $\tilde{\omega} \in \tilde{\Omega}$. These issues are illustrated in the following formalization of the consumer's choice problem.

\footnotetext{
${ }^{26}$ Since we need to accommodate zoning aspects in the end, it is hard to dispense with finite types of consumers. Given the finiteness of $\Theta$, we can use Konishi's (1996) simple fixed point mapping.
} 
If she chooses $\tilde{\omega}$, then type $\theta$ consumer's consumption bundle must lie $\mathrm{in}^{27}$

$$
\begin{aligned}
& X_{\tilde{\omega}}^{\theta} \equiv \underbrace{\mathbb{R}_{+}}_{\text {numeraire }} \times \underbrace{\{0\} \times \ldots \times\{0\}}_{\text {leisure } 1, \ldots, j_{\tilde{\omega}}-1} \times \underbrace{\left[0, \bar{\ell}_{j_{\tilde{\omega}}}^{\theta}\right]}_{\text {leisure } j_{\tilde{\omega}}} \times \underbrace{\{0\} \times \ldots \times\{0\}}_{\text {leisure } j_{\tilde{\omega}}+1, \ldots, J} \\
& \times \underbrace{\{0\} \times \ldots \times\{0\}}_{\text {land } 1, \ldots, j_{\tilde{\omega}}-1} \times \underbrace{\mathbb{R}_{+}}_{\text {land } j_{\tilde{\omega}}} \times \underbrace{\{0\} \times \ldots \times\{0\}}_{\text {land } j_{\tilde{\omega}}+1, \ldots, J} \\
& \times \underbrace{\{0\} \times \ldots \times\{0\}}_{\text {type } 1, \ldots, \tilde{\omega}-1} \times \underbrace{\{1\}}_{\text {type } \tilde{\omega}} \times \underbrace{\{0\} \times \ldots \times\{0\}}_{\text {type } \tilde{\omega}+1, \ldots,|\tilde{\Omega}|},
\end{aligned}
$$

where the last line represents an index function dependent on choice of jurisdiction type. That is, a jurisdiction type needs to be chosen as a consumption good. Since choice of $\tilde{\omega} \in \tilde{\Omega}$ is a discrete choice, her consumption set is written as

$$
X^{\theta}=\cup_{\tilde{\omega} \in \tilde{\Omega}} X_{\tilde{\omega}}^{\theta} .
$$

Let $X=\mathbb{R}^{1+2 J+|\tilde{\Omega}|}$ be such that $X^{\theta} \subset X$ for all $\theta \in \Theta$. With this setup, a typical element of consumption set $y \in X_{\tilde{\omega}}^{\theta} \subset X^{\theta}$ (when she chooses jurisdiction type $\tilde{\omega}$ ) looks like

$$
y=(\underbrace{x}_{\text {numeraire }} ; \underbrace{0, \ldots, 0, \underset{j_{\tilde{\omega}}^{\ell} \mathrm{th}}{\ell}, 0, \ldots, 0}_{\text {leisure }} ; \underbrace{0, \ldots, 0, \underset{j_{\tilde{\omega} \mathrm{th}}}{L}, 0, \ldots, 0}_{\text {land }} ; \underbrace{0, \ldots, 0, \underset{\tilde{\tilde{\omega t h h}}}{1}, 0, \ldots, 0)}_{\text {public project }} .
$$

Under a complete price system, a price vector is:

$$
p=\left(1 ;\left(w_{j}\right)_{j \in J} ;\left(r_{j}\right)_{j \in J} ;\left(\tau_{\tilde{\omega}}\right)_{\tilde{\omega} \in \tilde{\Omega}}\right) \in \mathbb{R}^{1+2 J+|\tilde{\Omega}|} .
$$

A type $\theta$ consumer's endowment when she chooses to live in location $j$ is written as

$$
e^{\theta}(j)=(\underbrace{0}_{\text {numeraire }} ; \underbrace{0, \ldots, 0, \bar{\ell}_{j}^{\theta}, 0, \ldots, 0}_{\text {leisure }} ; \underbrace{\bar{L}_{1}^{\theta}, \ldots, \bar{L}_{J}^{\theta}}_{\text {land }} ; \underbrace{0, \ldots, 0}_{\text {public project }}) .
$$

Thus, a type $\theta$ consumer's choice when she chooses location $j$ is:

$$
\max _{y \in \cup_{\tilde{\omega}}=j X_{\tilde{\omega}}^{\theta}} u_{j_{\omega}}^{\theta}\left(\operatorname{proj}_{\tilde{\omega}} y, g_{\tilde{\omega}}, n_{\tilde{\omega}}\right) \text { subject to } p \cdot y \leq p \cdot e^{\theta}(j),
$$

\footnotetext{
${ }^{27}$ Strictly speaking, it is not prohibited for a consumer to consume land in a location other than her residential location, but such land would be useless for her. Thus, we assume that she can consume land only at her residential location.
} 
where $\operatorname{proj}_{\tilde{\omega}} y=\left(\operatorname{proj}_{0} y, \operatorname{proj}_{\ell_{\tilde{\omega}}} y, \operatorname{proj}_{j_{\tilde{\omega}}} y\right)=(x, \ell, L)$.

One problem which arises in spatial models is that the value of a consumer's endowment depends on her location choice (see $(*)$ above). This does not arise in defining the consumer's choice problem, since she can compare the level of indirect utility at each location $j \in J$, and choose a location that attains the highest indirect utility. Thus, we can prove Proposition 1 in this setup. However, it does pose a problem for proving the efficiency of the equilibrium. The standard proof of the first welfare theorem relies on comparisons of values of consumption bundles/endowments. It is essential for the proof to have the same endowment values independent of consumers' location choices.

It turns out that this problem is not severe. We need only normalize the consumer's endowment to the origin so that the value of the endowment is always zero irrespective of her location choice. A consumption set with such a translation of the origin is called a trading set (McKenzie 1959). Once this translation is done, the standard argument proves the first welfare theorem. ${ }^{28}$ When a type $\theta$ consumer chooses $\tilde{\omega}$, then her trading set is

$$
\begin{aligned}
\bar{X}_{\tilde{\omega}}^{\theta} \equiv & \underbrace{\mathbb{R}_{+}}_{\text {numeraire }} \times \underbrace{\{0\} \times \ldots \times\{0\}}_{\text {leisure } 1, \ldots, j_{\tilde{\omega}}-1} \times \underbrace{\left[-\bar{\ell}_{j_{\tilde{\omega}}}^{\theta}, 0\right]}_{\text {leisure } j_{\tilde{\omega}}} \times \underbrace{}_{\text {leisure } \left.j_{\tilde{\omega}+1, \ldots, J} 0\right\} \times \ldots \times\{0\}} \\
& \times \underbrace{\left\{-\bar{L}_{1}^{\theta}\right\} \times \ldots \times\left\{-\bar{L}_{j_{\tilde{\omega}}-1}^{\theta}\right\}}_{\text {land } 1, \ldots, j_{\tilde{\omega}}-1} \times \underbrace{\left[-\bar{L}_{j_{\tilde{\omega}}}^{\theta}, \infty\right)}_{\text {land } j_{\tilde{\omega}}} \times \underbrace{}_{\text {land } j_{\tilde{\omega}+1, \ldots, J}\left\{-\bar{L}_{j_{\tilde{\omega}}+1}^{\theta}\right\} \times \ldots \times\left\{-\bar{L}_{J}^{\theta}\right\}} \\
& \times \underbrace{\{0\} \times \ldots \times\{0\}}_{\text {type } 1, \ldots, \tilde{\omega}-1} \times \underbrace{\{1\}}_{\text {type } \tilde{\omega}} \times \underbrace{\{0\} \times \ldots \times\{0\}}_{\text {type } \tilde{\omega}+1, \ldots,|\tilde{\Omega}|} .
\end{aligned}
$$

Since the choice of $\tilde{\omega} \in \tilde{\Omega}$ is discrete, her trading set is written as

$$
\bar{X}^{\theta}=\cup_{\tilde{\omega} \in \tilde{\Omega}} \bar{X}_{\tilde{\omega}}^{\theta}
$$

The utility function $u_{\tilde{\omega}}^{\theta}: X_{\tilde{\omega}}^{\theta} \rightarrow \mathbb{R}$ is also translated to $\bar{u}_{\tilde{\omega}}^{\theta}: \bar{X}_{\tilde{\omega}}^{\theta} \rightarrow \mathbb{R}$ accordingly.

Proposition 2. Every Tiebout equilibrium with poll taxes is Pareto efficient.

Next, we transform the poll taxes to pairs of policies: property taxes and zoning policies. First, note that for each Tiebout equilibrium with poll taxes,

\footnotetext{
${ }^{28}$ See Berliant and Konishi (2000). Note that the trading set approach is effective in a job choice model as well.
} 
we can construct another sorting Tiebout equilibrium with poll taxes: that is, in each jurisdiction there is only one type of consumer for almost all jurisdictions. This step is needed, since in a Tiebout equilibrium with poll taxes, two different types of consumers may choose the same $\tilde{\omega}$. If this were the case, then in an equilibrium allocation these two different types may live together in the same jurisdiction while choosing two different amounts of land. Obviously, a zoning policy cannot support such an allocation. For a zoning policy to work, we need perfect homogeneity in demand for land in each jurisdiction. To achieve perfect homogeneity, we need LP and FP. Under these assumptions, it is easy to see that there is always an equilibrium allocation in which each jurisdiction has a perfectly homogeneous population. If in a Tiebout equilibrium with poll taxes, $m_{\tilde{\omega}}^{\theta}>0$ and $m_{\tilde{\omega}}^{\theta^{\prime}}>0$ hold, then we can let measure $m_{\tilde{\omega}}^{\theta} / n_{\tilde{\omega}}$ type $\tilde{\omega}$ jurisdictions have only type $\theta$ residents and measure $m_{\tilde{\omega}}^{\theta^{\prime}} / n_{\tilde{\omega}}$ type $\tilde{\omega}$ jurisdictions have only type $\theta^{\prime}$ residents. We call such an equilibrium allocation a sorting Tiebout equilibrium allocation with poll taxes. ${ }^{29}$ Now we can construct the zoning policies. For each $\tilde{\omega} \in \tilde{\Omega}^{*}$, there is at least a $\theta \in \Theta$ with $m_{\tilde{\omega}}^{\theta}>0$. For them, we construct $\omega$ : i.e., a zoning policy $\zeta_{\omega}=z_{\omega}^{\theta}$ with $t_{\omega}=\tau_{\tilde{\omega}}=c\left(g_{\omega}\right) / n_{\omega} \zeta_{\omega}$. This works as a Hamilton zoning policy. The following two propositions establish the essential equivalence between Tiebout equilibrium with entrepreneurial jurisdictions and Tiebout equilibrium with poll taxes.

Proposition 3. Every sorting Tiebout equilibrium allocation with poll taxes can be supported by a Tiebout equilibrium with entrepreneurial jurisdictions.

Proposition 4. Every Tiebout equilibrium allocation with entrepreneurial jurisdictions can be supported by a sorting Tiebout equilibrium allocation with poll taxes.

These propositions clarify how the equilibrium concept of Rothschild and Stiglitz (1976) achieves efficient allocations: all types of consumers can achieve the highest possible utility under segregation. This key observation is summarized formally as follows.

\footnotetext{
${ }^{29}$ Strictly speaking, it may not be necessary to introduce different jurisdictions for all types. As Hamilton (1975) correctly points out, as long as two types $\theta$ and $\theta^{\prime}$ consume the same amount of land at $\tilde{\omega}$, zoning policies can support mixed jurisdictions by these types.
} 
Observation. In all Tiebout equilibria with entrepreneurial jurisdictions, $U^{\theta}\left(\omega ;\left(r_{j}^{*}, w_{j}^{*}\right)_{j \in J}\right)=\max _{\left\{\omega^{\prime} \in \Omega: t_{\omega} \zeta_{\omega} n_{\omega} \geq c\left(g_{\omega}\right)\right\}} U^{\theta}\left(\omega^{\prime} ;\left(r_{j}^{*}, w_{j}^{*}\right)_{j \in J}\right)$ for all $\theta \in \Theta$ and all $\omega \in \Omega^{*}$ with $m_{\omega}^{\theta}>0$.

That is, if type $\theta$ consumers choose jurisdiction type $\omega$ in the equilibrium, then their utility levels are the highest among all possible (including nonexisting) jurisdiction types that satisfy budget-balancing conditions. This is how our Tiebout equilibrium with entrepreneurial jurisdictions achieves efficiency through managers' entrepreneurship and consumers' self-selection given fiscally anonymous congestion.

\section{Concluding Remarks}

We can relax the conditions in the Theorem quite a bit. We actually do not need quasi-concavity of utility functions (convexity of preferences). We assumed convexity only for simplicity. Our theorem can be easily extended to a more general setting with many private goods, general (CRS) production technologies, and many different occupations. Conley and Wooders (1996) consider occupation choice with an occupation-dependent crowding type, and show that the equilibrium is efficient if an occupation-dependent nonanonymous tax can be imposed. In contrast, since we do not assume that crowding is type-dependent, if we just allow that utility and wage depend on occupation choice then such occupation-dependent taxes are not necessary to attain efficiency.

Note that our theorem holds only in an idealized situation, since it requires that there be very many jurisdictions for each location, which is not very realistic. If there are limited numbers of jurisdictions in each location, then two problems can occur: monopoly powers by jurisdictions, and insufficient choice sets provided by jurisdictions. Allowing free entry of new jurisdictions may sound reasonable in our setup, since it includes large numbers of negligibly small jurisdictions. However, in reality, unless there is unused land (or farm land or forest) in equilibrium, ${ }^{30}$ the implicit assumption of free entry does not seem easily justifiable. At least, the locations near central business districts should not have plenty of unused land. Moreover, the model is static, so our theorem does not touch on how to rearrange jurisdiction borders when a

\footnotetext{
${ }^{30}$ Bewley (1981) and Bruckner (1981) have discussions on this matter.
} 
new jurisdiction is set up, or on how to ask current residents to move from an existing jurisdiction that is not profitable. ${ }^{31}$ Thus, there is more friction in the presence of a spatial structure, and Tiebout's tale becomes harder to justify.

Despite the above cautious remark, our theorem may find another useful application in urban economic theory. We can apply directly our theorem to prove the existence and efficiency of a closed-economy monocentric city equilibrium with transport costs (in commuting time) when housing quality is endogenous as long as there is a finite number of rings of heterogeneous land (distinguished by the distance from the CBD). ${ }^{32}$ Houses and condo buildings are easier to demolish and rebuild than jurisdictions, so it might be easier to justify the free entry assumption in this case. In monocentric city models, housing and land are used almost interchangeably. However, in our model, if we interpret $g$ as a housing quality, we can let consumers choose their own housing qualities. Since multiple people can share the same $g$, we can deal with collective residential buildings (condos/apartments instead of houses). More formally, let us order locations $j_{0}, j_{1}, \ldots, j_{K}$, and assume that production can be made only in the CBD location $j_{0}$ : i.e., $\alpha_{j}=\infty$ for $j \neq j_{0}$, while $\alpha_{j_{0}}<\infty$. As index $k$ increases, the distance from the CBD increases. As a result, for all $\theta \in \Theta, \bar{\ell}_{j_{0}}^{\theta}>\bar{\ell}_{j_{1}}^{\theta}>\ldots>\bar{\ell}_{j_{K}}^{\theta}$ (commuting time difference). If the geography is one-dimensional (as in a linear city), then we may assume $\bar{L}_{j_{k}}=\bar{L}_{j_{k^{\prime}}}$ for all $k, k^{\prime} \in\{0,1, \ldots, K\}$. If it is two-dimensional, then we may assume $\bar{L}_{j_{0}}<\bar{L}_{j_{1}}<\ldots<\bar{L}_{j_{K}}$. We interpret $\omega=\left(g_{\omega}, n_{\omega}\right) \in \Omega$ as a building that can be a house or a condo/apartment: $g_{\omega}$ is a type of building (say, high quality, low quality, with a swimming pool, or with a nicely landscaped garden, etc.) and $n_{\omega}$ is the number of households living in the building (if $n_{\omega}=1$ then it is a single household house, and if $n_{\omega}$ is large it is an apartment complex). Our theorem says that there is an equilibrium sorting with various housing qualities including collective housing such as apartments. ${ }^{33}$ Assuming

\footnotetext{
${ }^{31}$ Berliant (1985) analyzes a formulation of parcel land market (say, total land endowment in an economy is a two-dimensional set, and each consumer consumes a subset of it without overlapping with other consumers' land consumption). He proves that a continuum economy (continuum of consumers) is inconsistent with parcel land market. Berliant and Fujita (1992) look at equilibrium in a spatial economy with parcel land and finite population. We avoid difficulties by assuming a quantity of land instead (the total land endowment of an economy is a quantity of land vector at all locations).

${ }^{32}$ See Fujita (1989) for many kinds of monocentric city models.

${ }^{33}$ Finiteness of locations may be dropped by applying the method by LaFountain (2006). In order to show efficiency of equilibrium, we need to assume that there are no congestion
} 
that land at each location is physically the same and that land is a normal good, it is easy to see that land prices go down as index $k$ increases, since choosing a smaller index location means more (potential) income for all $\theta \in$ $\Theta$. However, other characteristics of equilibrium allocations require further assumptions about consumers' preferences over $\Omega$ and the distributions of their land endowments. ${ }^{34}$

Actually, the "monocentric" assumption is not important for the existence and efficiency results. Even if a consumer can freely choose her locations of residence and work, our results are not affected. The only modification needed is to assume that each consumer (say type $\theta$ ) chooses a pair of locations: her residential location and working location, $\left(j, j^{\prime}\right) \in J \times J$, and her leisure endowment for the choice is $\bar{\ell}_{j j^{\prime}}^{\theta}$ since her commuting time depends on her residential and work locations (see the concluding remarks in Konishi 1996).

\section{Appendix}

Here we collect all proofs of Propositions.

Proposition 1. There exists a Tiebout equilibrium with poll taxes under the following assumptions:

1. For all $\theta \in \Theta$, all $j \in J$, all $g \in G$, all $n \in N=\{1, \ldots, \bar{n}\},, u_{j}^{\theta}(x, \ell, L, g, n)$ is continuous and strictly monotonic in $(x, \ell, L)$;

2. for all $\theta \in \Theta$, all $j \in J$, all $\ell_{j} \in\left[0, \bar{\ell}_{j}^{\theta}\right]$, all $L \in \mathbb{R}_{+}$, all $g \in G$, all $n \in\{1, \ldots, \bar{n}\}, u_{j}^{\theta}(0, \ell, L, g, n)=\underline{u}^{\theta}$ (essentiality of numeraire); and

3. for all $\theta \in \Theta$, all $j \in J$, all $g \in G$, and all $n=N \in\{1, \ldots, \bar{n}\}$, $u_{j}^{\theta}(x, \ell, L, g, n)$ is strictly quasi-concave in $(x, \ell, L)$.

Proof of Proposition 1. Although we normalized the numeraire price at unity in the set up, we actually need to have a compact price set. So it is more convenient for us to use a $J+1$ dimensional price simplex $\Delta \equiv\left\{\tilde{p} \in \mathbb{R}_{+}^{J+1}\right.$ :

externalities in commuting.

${ }^{34}$ It may be interesting to analyze the relationship between housing quality and distance from the CBD. 
$\left.\sum_{j=0}^{J} \tilde{p}_{j}=1\right\}$ (numeraire and land prices, where $\tilde{p}_{0}$ and $\tilde{p}_{j}(j \neq 0)$ represent the numeraire price and land price at location $j{ }^{35}$ respectively: wages and public project prices are tied up with the numeraire price by assumption ${ }^{36}$ ) We need to show that the relative price of the numeraire does not go to zero as well, but this is easily shown by considering a sequence of $\epsilon$-truncated price simplices $\Delta(\epsilon) \equiv\left\{\tilde{p} \in \mathbb{R}_{+}^{J+1}: \sum_{j=0}^{J} \tilde{p}_{j}=1\right.$ and $\left.\tilde{p}_{j} \geq \epsilon\right\}\left(\epsilon<\frac{1}{J+1}\right)$, and taking the limit of a sequence of $\epsilon$-equilibria (equilibria within $\epsilon$-truncated price simplex) as $\epsilon$ approaches zero (with assumption 1). For simplicity, we omit this procedure. ${ }^{37}$ With an abuse of notation, we let $\Delta=\Delta(\epsilon)$.

To make each consumer's consumption set compact, we truncate consumption sets by placing an upper bound on the numeraire and land consumption, and we take a sequence of equilibria for increasing upper bounds. ${ }^{38}$ The limit will be shown to be an equilibrium allocation (see, e.g., Hildenbrand 1972). For each $\theta$ and $\tilde{\omega}$, let $X_{\omega}^{\theta}(k)$ be such that

$$
X_{\tilde{\omega}}^{\theta}(k) \equiv X_{\tilde{\omega}}^{\theta} \cap[0, k]^{1+2 J+|\tilde{\Omega}|}
$$

and let $X^{\theta}(k)=\cup_{\tilde{\omega} \in \tilde{\Omega}} X_{\tilde{\omega}}^{\theta}(k)$, where $k=1,2, \ldots$. Obviously, for each $k, X^{\theta}(k)$ is a compact set.

For each $\theta \in \Theta$, let $\beta_{\tilde{\omega}}^{\theta}: \Delta \rightarrow X_{\tilde{\omega}}^{\theta}(k)$ be type $\theta$ 's budget correspondence at $\tilde{\omega} \in \tilde{\Omega}$ such that ${ }^{39}$

$\beta_{\tilde{\omega}}^{\theta}(\tilde{p})=\left\{(x, \ell, z) \in \operatorname{proj}_{\tilde{\omega}} X_{\tilde{\omega}}^{\theta}(k): \tilde{p}_{0} x+\tilde{p}_{j_{\tilde{\omega}}} z+\tau_{\tilde{\omega}} \leq \frac{\tilde{p}_{0}}{\alpha_{j_{\tilde{\omega}}}}\left(\bar{\ell}_{j_{\tilde{\omega}}}^{\theta}-\ell\right)+\sum \tilde{p}_{\tilde{\omega}^{\prime}} \bar{L}_{j_{\tilde{\omega}^{\prime}}}^{\theta}\right\}$,

where $\tau_{\tilde{\omega}}=\tilde{p}_{0} c\left(g_{\tilde{\omega}}\right) / n_{\tilde{\omega}}$ (condition 6). Although $\beta_{\tilde{\omega}}^{\theta k}$ is compact-valued, it can be empty-valued for some $\tilde{p}$ s due to a poll tax $\tau_{\tilde{\omega}}$. Under such $\tilde{p}$ s, type $\theta$

\footnotetext{
${ }^{35}$ Thus, $r_{j}=\tilde{p}_{j} / \tilde{p}_{0}$.

${ }^{36}$ It is easy to endogenize wages and public project prices using flexible production technologies.

${ }^{37}$ The procedure of taking a limit is routine (for a spatial economy, see Konishi 1996, Lemma 3). Basically, the result holds by upper hemicontinuity of best response correspondences.

${ }^{38}$ If the number of consumers if finite, we do not need this procedure: each consumer's feasible consumption plan is bounded. However, in an atomless economy, each consumer's feasible consumption set is unbounded since the measure of consumers who live in a location can be very small, which in turn means that each consumer's consumption plan in such a location can be very large. This is why we need to take the limit of an equilibrium sequence.

${ }^{39}$ Although correspondence $\beta_{\tilde{\omega}}^{\theta}$ is dependent on $k$, we omit $k$ to simplify the notation. The same comment applies to $\delta_{\tilde{\omega}}^{\theta}, \tilde{U}^{\theta}$ and others.
} 
consumer cannot live in jurisdiction $\tilde{\omega}$. In order to overcome this emptiness problem, let $\Delta_{\tilde{\omega}}^{\theta} \equiv\left\{\tilde{p} \in \Delta: \tau_{\tilde{\omega}}<\frac{\tilde{p}_{0}}{\alpha_{j \tilde{\omega}}}\left(\bar{\ell}_{j}^{\theta}-\ell\right)+\sum \tilde{p}_{\tilde{\omega}_{\tilde{\omega}^{\prime}}} \bar{L}_{\tilde{j}_{\tilde{\omega}^{\prime}}}^{\theta}\right\}$ be the set of price vectors in which type $\theta$ consumer's budget set at $\tilde{\omega}$ has a cheaper point. Note that $\Delta_{\tilde{\omega}}^{\theta}$ is open relative to $\Delta$. Let $\delta_{\tilde{\omega}}^{\theta}: \Delta_{\tilde{\omega}}^{\theta} \rightarrow \mathbb{R}_{+} \times\left[0, \bar{\ell}_{j}^{\theta}\right] \times \mathbb{R}_{+}$be type $\theta^{\prime}$ s demand correspondence when she is forced to choose $\tilde{\omega} \in \tilde{\Omega}$ such that

$\delta_{\tilde{\omega}}^{\theta}(\tilde{p})=\left\{(x, \ell, z) \in \beta_{\tilde{\omega}}^{\theta}(\tilde{p}): u_{j_{\tilde{\omega}}}^{\theta}\left(x, \ell, z, g_{\tilde{\omega}}, n_{\tilde{\omega}}\right) \geq u_{j_{\tilde{\omega}}}^{\theta}\left(x^{\prime}, \ell^{\prime}, z^{\prime}, g_{\tilde{\omega}}, n_{\tilde{\omega}}\right) \forall\left(x^{\prime}, \ell^{\prime}, z^{\prime}\right) \in \beta_{\tilde{\omega}}^{\theta}(\tilde{p})\right\}$.

By Weierstrass's theorem and Berge's maximum theorem, $\delta_{\tilde{\omega}}^{\theta}$ is nonemptyvalued and upper hemicontinuous. Moreover, strict quasi-concavity guarantees single-valuedness. That is, $\delta_{\tilde{\omega}}^{\theta}$ is a continuous function.

Now, we will move toward consumers' jurisdiction choice mapping. One obstacle we need to overcome is how to extend the domain of the above demand correspondence to $\Delta$ without affecting the consumers' actual choice correspondence. Let $\bar{\delta}_{\tilde{\omega}}^{\theta}: \Delta \rightarrow X_{\tilde{\omega}}^{\theta}(k)$ be such that

$$
\bar{\delta}_{\tilde{\omega}}^{\theta}(\tilde{p})=\left\{\begin{array}{cl}
\delta_{\tilde{\omega}}^{\theta}(\tilde{p}) & \text { if } \tilde{p} \in \Delta_{\tilde{\omega}}^{\theta} \\
0 & \text { if } \tilde{p} \notin \Delta_{\tilde{\omega}}^{\theta}
\end{array}\right.
$$

This is again a continuous function. ${ }^{40}$ Note that Assumption 2 says that type $\theta$ consumers get $\underline{u}^{\theta}$ in the latter case. For each $\tilde{p} \in \Delta_{\tilde{\omega}}^{\theta}$, let $\tilde{U}^{\theta}(\tilde{\omega} ; \tilde{p}) \equiv$ $u_{j_{\tilde{\omega}}}^{\theta}\left(\bar{\delta}_{\tilde{\omega}}^{\theta}(\tilde{p})\right)$. This is a continuous function. Now, we can construct type $\theta$ consumer's jurisdiction choice mapping. Let $\lambda^{\theta}: \Delta \rightarrow \tilde{\Omega}$ be such that $\lambda^{\theta}(\tilde{p})=$ $\left\{\tilde{\omega} \in \tilde{\Omega}: \tilde{U}^{\theta}(\tilde{\omega} ; \tilde{p})=\max \tilde{U}^{\theta}\left(\tilde{\omega}^{\prime} ; \tilde{p}\right)\right\}$. By Berge's maximum theorem, $\lambda^{\theta}$ is an upper hemicontinuous correspondence. Since we allow $\emptyset \in G$ (no public project) with $c(\emptyset)=0$, as long as the price of the numeraire is positive, there is an $\tilde{\omega} \in \tilde{\Omega}$ with $\Delta_{\tilde{\omega}}^{\theta}=\Delta$ for $g_{\tilde{\omega}}=\emptyset$ (denote $\left.\tilde{\omega}_{\emptyset}\right)$. Thus, for all $\tilde{p} \in \Delta$, and all $\theta \in \Theta$, for $\tilde{\omega}_{\emptyset} \in \tilde{\Omega}$ there is a cheaper point in her budget constraint. Thus, $\tilde{U}^{\theta}\left(\tilde{\omega}_{\emptyset} ; \tilde{p}\right)>\underline{u}^{\theta}$ for all $\tilde{p} \in \Delta$ by Assumptions 1 and 2 . This assures that for all price vectors $\tilde{p} \in \Delta$, each type $\theta$ obtains a utility strictly higher than $\underline{u}^{\theta}$, which makes type $\theta$ consumers' choices under $\tilde{p} \notin \Delta_{\tilde{\omega}}^{\theta}$ (and extension parts of $\left.\bar{\delta}_{\tilde{\omega}}^{\theta}\right)$ irrelevant. That is, if $\tilde{\omega} \in \lambda^{\theta}(\tilde{p})$ then $\tilde{p} \in \Delta_{\tilde{\omega}}^{\theta}$. Since type $\theta$ consumers are indifferent among $\lambda^{\theta}(\tilde{p})$, their optimal location choices generate a population distribution defined by the following population mapping: $\mu^{\theta}: \Delta \rightarrow M^{\theta}$, where $M^{\theta}=\left\{\left(m_{\tilde{\omega}}^{\theta}\right)_{\tilde{\omega} \in \tilde{\Omega}} \in \mathbb{R}_{+}^{\tilde{\Omega}}: \sum_{\tilde{\omega} \in \tilde{\Omega}} m_{\tilde{\omega}}^{\theta}=m^{\theta}\right\}$, such that

$$
\mu^{\theta}(\tilde{p})=\left\{\left(m_{\tilde{\omega}}^{\theta}\right)_{\tilde{\omega} \in \tilde{\Omega}} \in M^{\theta}: m_{\tilde{\omega}}^{\theta}>0 \text { only if } \tilde{\omega} \in \lambda^{\theta}(\tilde{p})\right\} .
$$

\footnotetext{
${ }^{40}$ As long as the price vector is positive, the budget constraint at $\tilde{\omega}$ shrinks to the origin around the boundary of $\Delta_{\tilde{\omega}}^{\theta}$, so $\bar{\delta}_{\tilde{\omega}}^{\theta}$ is a continuous function.
} 
It is easy to see that $\mu^{\theta}$ is upper hemicontinuous and convex-valued. Let $\mu: \Delta \rightarrow \Pi_{\theta \in \Theta} M^{\theta}$ be such that $\mu(\tilde{p}) \equiv \Pi_{\theta \in \Theta} \mu^{\theta}(\tilde{p})$ for all $\tilde{p} \in \Delta$.

Next, we move on to excess demand correspondence (in the numeraire and land markets). First, let the feasible excess demand set under the population distribution $m=\left(m_{\tilde{\omega}}^{\theta}\right)_{\theta \in \Theta, \tilde{\omega} \in \tilde{\Omega}} \in \Pi_{\theta \in \Theta} M^{\theta}$ be:

$$
\begin{aligned}
F(m) \equiv & \left\{\left\{\left(f_{0}, f_{1}, \ldots, f_{J}\right) \in \mathbb{R} \times \mathbb{R}^{J}:\right.\right. \\
& f_{0}=\sum_{\theta \in \Theta, \tilde{\omega} \in \tilde{\Omega}} m_{\tilde{\omega}}^{\theta} x_{\tilde{\omega}}^{\theta}-\sum_{j \in J} \frac{1}{\alpha_{j}} \times \sum_{\theta \in \Theta} \sum_{\tilde{\omega} \in \tilde{\Omega}, j_{\tilde{\omega}}=j} m_{\tilde{\omega}}^{\theta}\left(\bar{\ell}_{j}^{\theta}-\ell_{j}^{\theta}\right)-\sum_{\tilde{\omega} \in \tilde{\Omega}} \sum_{\theta \in \Theta} m_{\tilde{\omega}}^{\theta} \times \frac{c\left(g_{\tilde{\omega}}\right)}{n_{\tilde{\omega}}}, \\
& \text { and } f_{j}=\sum_{\theta \in \Theta} \sum_{\tilde{\omega} \in \tilde{\Omega}, j_{\tilde{\omega}}=j} m_{\tilde{\omega}}^{\theta} z_{\tilde{\omega}}^{\theta}-\bar{L}_{j} \text { for all } j \in J \\
& \text { for a vector } \left.\left(x_{\tilde{\omega}}^{\theta}, \ell_{\tilde{\omega}}^{\theta}, z_{\tilde{\omega}}^{\theta}\right)_{\theta \in \Theta, \tilde{\omega} \in \tilde{\Omega}} \text { that is consistent with } X_{\tilde{\omega}}^{\theta}(k) \text { for all } \theta \text { and } \tilde{\omega}\right\} .
\end{aligned}
$$

Let $F \equiv c o\left(\cup_{m \in \Pi_{\theta \in \Theta} M^{\theta}} F(m)\right)$, where $c o(\cdot)$ denotes a convex hull of $\cdot$ For excess demand correspondence: Let $\psi: \prod_{\theta \in \Theta \tilde{\omega} \in \tilde{\Omega}} X_{\omega}^{\theta}(k) \times \prod_{\theta \in \Theta} M^{\theta} \rightarrow F$ be such that

$$
\begin{aligned}
& \psi_{0}\left(\left(x_{\tilde{\omega}}^{\theta}, \ell_{\tilde{\omega}}^{\theta}, z_{\tilde{\omega}}^{\theta}, m_{\tilde{\omega}}^{\theta}\right)_{\theta \in \Theta, \tilde{\omega} \in \tilde{\Omega}}\right) \\
= & \sum_{\theta \in \Theta, \tilde{\omega} \in \tilde{\Omega}} m_{\tilde{\omega}}^{\theta} x_{\tilde{\omega}}^{\theta}-\sum_{j \in J} \frac{1}{\alpha_{j}} \times \sum_{\theta \in \Theta} \sum_{\tilde{\omega} \in \tilde{\Omega}, j \tilde{\omega}=j} m_{\tilde{\omega}}^{\theta}\left(\bar{\ell}_{j}^{\theta}-\ell_{j}^{\theta}\right)-\sum_{\tilde{\omega} \in \tilde{\Omega}} \sum_{\theta \in \Theta} m_{\tilde{\omega}}^{\theta} \times \frac{c\left(g_{\tilde{\omega}}\right)}{n_{\tilde{\omega}}},
\end{aligned}
$$

and

$$
=\sum_{\theta \in \Theta} \sum_{\tilde{\omega} \in \tilde{\Omega}, j_{\tilde{\omega}}=j} m_{\tilde{\omega}}^{\theta} z_{\tilde{\omega}}^{\theta}-\bar{L}_{j} \text { for all } j \in J .
$$

It is clear that $\psi$ is a continuous function. Finally, we define a price mapping based on Gale-Nikaido's lemma. Let $\pi: F \rightarrow \Delta$ be such that

$$
\pi(f)=\left\{\tilde{p} \in \Delta: \tilde{p} \cdot f \geq \tilde{p}^{\prime} \cdot f \text { for all } \tilde{p}^{\prime} \in \Delta\right\} .
$$

It is clear that $\pi$ is nonempty-valued, upper hemicontinuous, and convexvalued.

Our fixed point mapping is

$$
\xi: \Delta \times \prod_{\theta \in \Theta, \tilde{\omega} \in \tilde{\Omega}} X_{\omega}^{\theta}(k) \times \prod_{\theta \in \Theta} M^{\theta} \times F \rightarrow \Delta \times \prod_{\theta \in \Theta, \tilde{\omega} \in \tilde{\Omega}} X_{\omega}^{\theta}(k) \times \prod_{\theta \in \Theta} M^{\theta} \times F
$$


which is a Cartesian product of

$$
\begin{aligned}
\pi & : F \rightarrow \Delta, \\
\bar{\delta} & : \Delta \rightarrow \prod_{\theta \in \Theta, \tilde{\omega} \in \tilde{\Omega}} X_{\omega}^{\theta}(k), \\
\mu & : \Delta \rightarrow \prod_{\theta \in \Theta} M^{\theta}, \\
\psi & : \prod_{\theta \in \Theta, \tilde{\omega} \in \tilde{\Omega}} X_{\omega}^{\theta}(k) \times \prod_{\theta \in \Theta} M^{\theta} \rightarrow F .
\end{aligned}
$$

By construction, we know that $\Delta, X_{\omega}^{\theta}(k), M^{\theta}$ and $F$ are nonempty, compact, convex sets, and from our analysis, we also know that $\pi, \bar{\delta}, \mu$ and $\psi$ are all nonempty-valued, upper hemicontinuous, and convex-valued correspondences. Since a product of upper hemicontinuous correspondences is upper hemicontinuous, ${ }^{41}$ the fixed point mapping is upper hemicontinuous. Thus, we can apply the Kakutani fixed point theorem, and there exists a fixed point

$$
\left(\tilde{p},\left(x_{\tilde{\omega}}^{\theta}, \ell_{\tilde{\omega}}^{\theta}, z_{\tilde{\omega}}^{\theta}, m_{\tilde{\omega}}^{\theta}\right)_{\theta \in \Theta, \tilde{\omega} \in \tilde{\Omega}}, f\right) \in \xi\left(\tilde{p},\left(x_{\tilde{\omega}}^{\theta}, \ell_{\tilde{\omega}}^{\theta}, z_{\tilde{\omega}}^{\theta}, m_{\tilde{\omega}}^{\theta}\right)_{\theta \in \Theta, \tilde{\omega} \in \tilde{\Omega}}, f\right) .
$$

The Gale-Nikaido's lemma (see Debreu 1959) proves the clearance of markets (conditions 3 and 5 with inequalities: 4 is already built in). Conditions 1 and 2 follow from the constructions of $\bar{\delta}$ and $\mu$. Condition 6 has been built in to the analysis. Thus, all conditions hold assuming that $x_{\tilde{\omega}}^{\theta} \in X_{\tilde{\omega}}^{\theta}(k)$ is indeed the optimal choice (at $\tilde{\omega})$ for nontruncated consumption set $X_{\tilde{\omega}}^{\theta}$. But this assumption does not necessarily hold. Thus, we take $k$ to infinity, and construct a sequence of fixed points of $\xi$. In the space of aggregated consumption, this sequence converges, and we can find an equilibrium (see Konishi 1996). Finally, we take $\epsilon$ to zero, and show that in equilibrium the numeraire has a positive price $\left(\tilde{p}_{0}>0\right)$ and thus, we can use another normalization $p_{0}=1$ as is done in the main text. ${ }^{42}$

Proposition 2. Every Tiebout equilibrium with poll taxes is Pareto efficient.

Proof of Proposition 2. We will focus on "equal-treatment" allocations within the same type and the same location: that is, all consumers of the same

\footnotetext{
${ }^{41} \mathrm{~A}$ product of closed graphs is a closed graph.

${ }^{42}$ At some locations, land price may become zero (measure zero consumers reside). Our assumptions do not prevent this from happening. Assumption 2 does not exclude the following situation: at a location, consumers' utilities are bounded above (by unattractiveness of the location), and in equilibrium, nobody resides at the location despite free land.
} 
type and the same location choice are assigned to the same consumption bundle (the same element in the trading set). Since we are assuming a quasi-concave utility function, if there is a Pareto-superior unequal-treatment allocation over an equilibrium allocation, then there is another equal-treatment allocation that is also Pareto-superior to the same equilibrium allocation. Hence, we can focus on equal-treatment allocations. ${ }^{43}$ An (equal treatment) allocation in trading sets is a list $\left(m_{\tilde{\omega}}^{\theta}, \bar{y}_{\tilde{\omega}}^{\theta}\right)_{\theta \in \Theta, \tilde{\omega} \in \tilde{\Omega}}$ such that, $\bar{y}_{\tilde{\omega}}^{\theta} \in \bar{X}_{\tilde{\omega}}^{\theta}$ for all $\theta \in \Theta$ and all $\tilde{\omega} \in \tilde{\Omega}$. Let $\operatorname{proj}_{L} \bar{y}=\left(\bar{y}_{L_{j}}\right)_{j \in J}$, $\operatorname{proj}_{\ell_{j}} \bar{y}=\bar{y}_{\ell_{j}}$ and $\operatorname{proj}_{x} \bar{y}=\bar{y}_{x}$ for $\bar{y} \in \cup_{\theta \in \Theta} \bar{X}^{\theta}$. A feasible allocation in trading sets is an allocation in trading sets $\left(m_{\tilde{\omega}}^{\theta}, \bar{y}_{\tilde{\omega}}^{\theta}\right)_{\theta \in \Theta, \tilde{\omega} \in \tilde{\Omega}}$ that satisfies:

(i) $\sum_{\tilde{\omega} \in \tilde{\Omega}} \sum_{\theta \in \Theta} m_{\tilde{\omega}}^{\theta} \operatorname{proj}_{L} \bar{y}_{\tilde{\omega}}^{\theta} \leq 0$, and

(ii) $\sum_{\tilde{\omega} \in \tilde{\Omega}} \sum_{\theta \in \Theta} m_{\tilde{\omega}}^{\theta} \operatorname{proj}_{x} \bar{y}_{\tilde{\omega}}^{\theta}+\sum_{j \in J} \frac{1}{\alpha_{j}} \sum_{\tilde{\omega} \in \tilde{\Omega}, j_{\tilde{\omega}}=j} \sum_{\theta \in \Theta} m_{\tilde{\omega}}^{\theta} \operatorname{proj}_{\ell_{j}} \bar{y}_{\tilde{\omega}}^{\theta}$ $+\sum_{\tilde{\omega} \in \tilde{\Omega}} \sum_{\theta \in \Theta} m_{\tilde{\omega}}^{\theta} \frac{c\left(g_{\tilde{\omega}}\right)}{n_{\tilde{\omega}}} \leq 0$.

A feasible allocation in trading sets $\left(m_{\tilde{\omega}}^{\theta}, \bar{y}_{\tilde{\omega}}^{\theta}\right)_{\theta \in \Theta, \tilde{\omega} \in \tilde{\Omega}}$ satisfies strict equaltreatment if for all $\theta \in \Theta$ and all $\tilde{\omega}, \tilde{\omega}^{\prime} \in \tilde{\Omega}$ with $m_{\tilde{\omega}}^{\theta}>0$ and $m_{\tilde{\omega}^{\prime}}^{\theta}>0$,

$$
\begin{aligned}
& \bar{u}^{\theta}\left(\operatorname{proj}_{x} \bar{y}_{\tilde{\omega}^{\prime}}^{\theta}, \operatorname{proj}_{\ell_{\tilde{\omega}^{\prime}}} \bar{y}_{\tilde{\omega}^{\prime}}^{\theta}, \operatorname{proj}_{L_{\tilde{\omega}_{\tilde{\omega}}}} \bar{y}_{\tilde{\omega}^{\prime}}^{\theta}, g_{\tilde{\omega}^{\prime}}, n_{\tilde{\omega}^{\prime}}\right) \\
= & \bar{u}^{\theta}\left(\operatorname{proj}_{x} \bar{y}_{\tilde{\omega}}^{\theta}, \operatorname{proj}_{\ell_{j_{\tilde{\omega}}}} \bar{y}_{\tilde{\omega}}^{\theta}, \operatorname{proj}_{L_{j_{\tilde{\omega}}}} \bar{y}_{\tilde{\omega}}^{\theta}, g_{\tilde{\omega}}, n_{\tilde{\omega}}\right) .
\end{aligned}
$$

Strict equal-treatment requires that as long as two consumers are of the same type, their utilities need to be the same irrespective of their jurisdiction choices. Note that all allocations of Tiebout equilibria with poll taxes satisfy strict equaltreatment.

A feasible allocation in trading sets $\left(m_{\tilde{\omega}}^{\theta}, \bar{y}_{\tilde{\omega}}^{\theta}\right)_{\theta \in \Theta, \tilde{\omega} \in \tilde{\Omega}}$ with equal-treatment is Pareto efficient ${ }^{44}$ if there is no feasible allocation in trading sets $\left(m_{\tilde{\omega}}^{\theta \prime}, \bar{y}_{\tilde{\omega}}^{\theta \prime}\right)_{\theta \in \Theta, \tilde{\omega} \in \tilde{\Omega}}$ such that

\footnotetext{
${ }^{43}$ The quasi-concavity of the utility function is actually not necessary. This assumption is made only to make the argument simple and elementary. We can use Aumann's (1964) measure-theoretical general equilibrium to show the same result without quasi-concavity (see Hildenbrand 1974). The key to proving the first welfare theorem in a spatial environment is using McKenzie's trading sets.

${ }^{44}$ For our purposes, it is sufficient to define Pareto efficiency of a feasible allocation with strict equal-treatment.
} 
(i) for all $\theta \in \Theta$, all $\tilde{\omega}, \tilde{\omega}^{\prime} \in \tilde{\Omega}$ with $m_{\tilde{\omega}}^{\theta}>0$ and $m_{\tilde{\omega}^{\prime}}^{\theta \prime}>0$,

$$
\begin{aligned}
& \bar{u}^{\theta}\left(\operatorname{proj}_{x} \bar{y}_{\tilde{\omega}^{\prime}}^{\theta \prime}, \operatorname{proj}_{\ell_{j_{\tilde{\omega}}}} \bar{y}_{\tilde{\omega}^{\prime}}^{\theta \prime}, \operatorname{proj}_{L_{j_{\tilde{\omega}}^{\prime}}} \bar{y}_{\tilde{\omega}^{\prime}}^{\theta \prime}, g_{\tilde{\omega}^{\prime}}, n_{\tilde{\omega}^{\prime}}\right) \\
\geq & \bar{u}^{\theta}\left(\operatorname{proj}_{x} \bar{y}_{\tilde{\omega}}^{\theta}, \operatorname{proj}_{\ell_{j_{\tilde{\omega}}}} \bar{y}_{\tilde{\omega}}^{\theta}, \operatorname{proj}_{L_{j_{\tilde{\omega}}}} \bar{y}_{\tilde{\omega}}^{\theta}, g_{\tilde{\omega}}, n_{\tilde{\omega}}\right)
\end{aligned}
$$

(ii) for some $\tilde{\omega}, \tilde{\omega}^{\prime} \in \tilde{\Omega}$ with $m_{\tilde{\omega}}^{\theta}>0$ and $m_{\tilde{\omega}^{\prime}}^{\theta \prime}>0$,

$$
\begin{aligned}
& \bar{u}^{\theta}\left(\operatorname{proj}_{x} \bar{y}_{\tilde{\omega}^{\prime}}^{\theta \prime}, \operatorname{proj}_{\ell_{j_{\tilde{\omega}}}} \bar{y}_{\tilde{\omega}^{\prime}}^{\theta \prime}, \operatorname{proj}_{L_{\tilde{j}_{\tilde{\omega}}}} \bar{y}_{\tilde{\omega}^{\prime}}^{\theta \prime}, g_{\tilde{\omega}^{\prime}}, n_{\tilde{\omega}^{\prime}}\right) \\
> & \bar{u}^{\theta}\left(\operatorname{proj}_{x} \bar{y}_{\tilde{\omega}}^{\theta}, \operatorname{proj}_{\ell_{j_{\tilde{\omega}}}} \bar{y}_{\tilde{\omega}}^{\theta}, \operatorname{proj}_{L_{j_{\tilde{\omega}}}} \bar{y}_{\tilde{\omega}}^{\theta}, g_{\tilde{\omega}}, n_{\tilde{\omega}}\right) .
\end{aligned}
$$

By using the above representation in trading sets, a Tiebout equilibrium with poll taxes can be represented in the following way. Let $p \in \mathbb{R}_{+}^{1+2 J+|\tilde{\Omega}|}$ be such that

$$
p=\left(1,\left(\frac{1}{\alpha_{j}}\right)_{j \in J},\left(r_{j}\right)_{j \in J},\left(\frac{c\left(g_{\tilde{\omega}}\right)}{n_{\tilde{\omega}}}\right)_{\tilde{\omega} \in \tilde{\Omega}}\right) .
$$

Note that the definition of $p$ includes zero profit conditions by jurisdictions, and profit maximizing firms (Conditions 4 and 6). Feasibility requires Conditions 3 and 5 . Thus, what is left is utility maximization by consumers (Conditions 1 and 2), and the following lemma is a straightforward consequence.

Lemma. A Tiebout equilibrium with poll taxes can be represented as a list of a price vector and a feasible allocation in trading sets $\left(p^{*},\left(m_{\tilde{\omega}}^{\theta}, \bar{y}_{\tilde{\omega}}^{\theta}\right)_{\theta \in \Theta, \tilde{\omega} \in \tilde{\Omega}}\right)$ such that $\bar{y}_{\tilde{\omega}}^{\theta} \in \arg \max _{y \in \bar{\beta}_{\tilde{\omega}}^{\theta}\left(p^{*}\right)} \bar{u}_{\tilde{\omega}}^{\theta}\left(\operatorname{proj}_{x} y, \operatorname{proj}_{\ell_{\tilde{\omega}}} y, \operatorname{proj}_{L_{\tilde{\omega}}} y, g_{\tilde{\omega}}, n_{\tilde{\omega}}\right)$ holds for $\tilde{\omega} \in \tilde{\Omega}$ with $m_{\tilde{\omega}}^{\theta}>0$, where $\bar{\beta}_{\tilde{\omega}}^{\theta}\left(p^{*}\right)=\left\{y \in \bar{X}_{\tilde{\omega}}^{\theta}: p^{*} \cdot y \leq 0\right\}$.

With this representation, we can prove the first welfare theorem. Let $\left(p^{*},\left(m_{\tilde{\omega}}^{\theta *}, \bar{y}_{\tilde{\omega}}^{\theta *}\right)_{\theta \in \Theta, \tilde{\omega} \in \tilde{\Omega}}\right)$ be a Tiebout equilibrium with poll taxes. Suppose that there exists a feasible allocation in trading sets $\left(m_{\tilde{\omega}}^{\theta \prime}, \bar{y}_{\tilde{\omega}}^{\theta \prime}\right)_{\theta \in \Theta, \tilde{\omega} \in \tilde{\Omega}}$ such that

(i) for all $\theta \in \Theta$, all $\tilde{\omega}, \tilde{\omega}^{\prime} \in \tilde{\Omega}$ with $m_{\tilde{\omega}}^{\theta *}>0$ and $m_{\tilde{\omega}^{\prime}}^{\theta \prime}>0$,

$$
\begin{aligned}
& \bar{u}^{\theta}\left(\operatorname{proj}_{x} \bar{y}_{\tilde{\omega}^{\prime}}^{\theta \prime}, \operatorname{proj}_{\ell_{\tilde{\omega}^{\prime}}} \bar{y}_{\tilde{\omega}^{\prime}}^{\theta \prime}, \operatorname{proj}_{L_{\tilde{\omega}^{\prime}}} \bar{y}_{\tilde{\omega}^{\prime}}^{\theta \prime}, g_{\tilde{\omega}^{\prime}}, n_{\tilde{\omega}^{\prime}}\right) \\
\geq & \bar{u}^{\theta}\left(\operatorname{proj}_{x} \bar{y}_{\tilde{\omega}}^{\theta *}, \operatorname{proj}_{\ell_{j_{\tilde{\omega}}}} \bar{y}_{\tilde{\omega}}^{\theta *}, \operatorname{proj}_{j_{j_{\tilde{\omega}}}} \bar{y}_{\tilde{\omega}}^{\theta *}, g_{\tilde{\omega}}, n_{\tilde{\omega}}\right) ;
\end{aligned}
$$

and 
(ii) for some $\tilde{\omega}, \tilde{\omega}^{\prime} \in \tilde{\Omega}$ with $m_{\tilde{\omega}}^{\theta *}>0$ and $m_{\tilde{\omega}^{\prime}}^{\theta \prime}>0$,

$$
\begin{aligned}
& \bar{u}^{\theta}\left(\operatorname{proj}_{x} \bar{y}_{\tilde{\omega}^{\prime}}^{\theta \prime}, \operatorname{proj}_{\ell_{\tilde{\omega}^{\prime}}} \bar{y}_{\tilde{\omega}^{\prime}}^{\theta \prime}, \operatorname{proj}_{L_{j_{\tilde{\omega}}^{\prime}}} \bar{y}_{\tilde{\omega}^{\prime}}^{\theta \prime}, g_{\tilde{\omega}^{\prime}}, n_{\tilde{\omega}^{\prime}}\right) \\
> & \bar{u}^{\theta}\left(\operatorname{proj}_{x} \bar{y}_{\tilde{\omega}}^{\theta *}, \operatorname{proj}_{\ell_{\tilde{\omega}}} \bar{y}_{\tilde{\omega}}^{\theta *}, \operatorname{proj}_{j_{\tilde{\omega}}} \bar{y}_{\tilde{\omega}}^{\theta *}, g_{\tilde{\omega}}, n_{\tilde{\omega}}\right) .
\end{aligned}
$$

Since utility functions are monotonic, consumers' budget constraints are binding in utility maximization under a Tiebout equilibrium with poll taxes. Thus, by (i) $p^{*} \cdot \bar{y}_{\tilde{\omega}}^{\theta \prime} \geq 0$ for all $\theta \in \Theta$ and all $\tilde{\omega} \in \tilde{\Omega}$ with $m_{\tilde{\omega}}^{\theta \prime}>0$, and by (ii) $p^{*} \cdot \bar{y}_{\tilde{\omega}}^{\theta \prime}>0$ for all $\theta \in \Theta$ and all $\tilde{\omega} \in \tilde{\Omega}$ with $m_{\tilde{\omega}}^{\theta \prime}>0$. Thus, we have

$$
\begin{aligned}
& \sum_{\tilde{\omega} \in \tilde{\Omega}} \sum_{\theta \in \Theta} m_{\tilde{\omega}}^{\theta \prime} \operatorname{proj}_{x} \bar{y}_{\tilde{\omega}}^{\theta \prime}+\sum_{j \in J} \frac{1}{\alpha_{j}} \sum_{\tilde{\omega} \in \tilde{\Omega}, j_{\tilde{\omega}}=j} \sum_{\theta \in \Theta} m_{\tilde{\omega}}^{\theta \prime} \operatorname{proj}_{\ell_{j}} \bar{y}_{\tilde{\omega}}^{\theta \prime} \\
& +\sum_{\tilde{\omega} \in \tilde{\Omega}} \sum_{\theta \in \Theta} m_{\tilde{\omega}}^{\theta \prime} \frac{c\left(g_{\tilde{\omega}}\right)}{n_{\tilde{\omega}}}+\sum_{\tilde{\omega} \in \tilde{\Omega}} \sum_{\theta \in \Theta} m_{\tilde{\omega}}^{\theta \prime}\left(r \cdot \operatorname{proj}_{L} \bar{y}_{\tilde{\omega}}^{\theta \prime}\right) \\
> & 0,
\end{aligned}
$$

where $r=\left(r_{j}\right)_{j \in J}$. Since the price of the numeraire is positive, and all land prices are nonnegative, we have either

$$
\sum_{\tilde{\omega} \in \tilde{\Omega}} \sum_{\theta \in \Theta} m_{\tilde{\omega}}^{\theta \prime} \operatorname{proj}_{x} \bar{y}_{\tilde{\omega}}^{\theta \prime}+\sum_{j \in J} \frac{1}{\alpha_{j}} \sum_{\tilde{\omega} \in \tilde{\Omega}, j_{\tilde{\omega}}=j} \sum_{\theta \in \Theta} m_{\tilde{\omega}}^{\theta \prime} \operatorname{proj}_{\ell_{j}} \bar{y}_{\tilde{\omega}}^{\theta \prime}+\sum_{\tilde{\omega} \in \tilde{\Omega}} \sum_{\theta \in \Theta} m_{\tilde{\omega}}^{\theta \prime} \frac{c\left(g_{\tilde{\omega}}\right)}{n_{\tilde{\omega}}}>0,
$$

or

$$
\sum_{\tilde{\omega} \in \tilde{\Omega}, j=j_{\tilde{\omega}}} \sum_{\theta \in \Theta} m_{\tilde{\omega}}^{\theta \prime} r_{j} \operatorname{proj}_{L_{j}} \bar{y}_{\tilde{\omega}}^{\theta \prime}>0 \quad \text { for some } j \in J .
$$

In the former case, there is excess demand for the numeraire, and in the latter case, at least in one location there is excess demand for land. Thus, $\left(m_{\tilde{\omega}}^{\theta \prime}, \bar{y}_{\tilde{\omega}}^{\theta \prime}\right)_{\theta \in \Theta, \tilde{\omega} \in \tilde{\Omega}}$ is infeasible. This is a contradiction. Thus, $\left(m_{\tilde{\omega}}^{\theta *}, \bar{y}_{\tilde{\omega}}^{\theta *}\right)_{\theta \in \Theta, \tilde{\omega} \in \tilde{\Omega}}$ is Pareto optimal.

Proposition 3. Every sorting Tiebout equilibrium allocation with poll taxes can be supported by a Tiebout equilibrium with entrepreneurial jurisdictions.

Proof of Proposition 3. For each $\tilde{\omega} \in \tilde{\Omega}$ and for each $\theta \in \Theta$, we will construct $\omega \in \Omega$. Let $\left(j_{\omega}, g_{\omega}, n_{\omega}\right)=\left(j_{\tilde{\omega}}, g_{\tilde{\omega}}, n_{\tilde{\omega}}\right)$ and $t_{\omega} \equiv \frac{\tau_{\tilde{\omega}}^{\theta}}{n_{\tilde{\omega}}^{\theta} z_{\tilde{\omega}}^{\theta}}$, and $\zeta_{\omega} \equiv z_{\tilde{\omega}}^{\theta}$. Collecting all these types of jurisdictions, we can construct set $\bar{\Omega}$. Let $\Omega^{*} \equiv$ 
$\left\{\omega \in \bar{\Omega}: m_{\tilde{\omega}}^{\theta}>0\right\}$. First, it is easy to see that if a type $\theta$ consumer lives in a type $\omega$ jurisdiction (constructed by $\tilde{\omega}$ and $\theta$ ), then she chooses to consume $\left(x_{\tilde{\omega}}^{\theta}, \ell_{\tilde{\omega}}^{\theta}, \zeta_{\omega}\right)=\left(x_{\tilde{\omega}}^{\theta}, \ell_{\tilde{\omega}}^{\theta}, z_{\tilde{\omega}}^{\theta}\right)$. Her budget constraint under the zoning constraint is

$$
x+\left(r_{j_{\omega}}^{*}+t_{\omega}\right) z \leq w_{j_{\omega}}^{*}\left(\bar{\ell}_{j}^{\theta}-\ell\right)+\sum r_{j_{\omega}}^{*} \bar{L}_{j_{\omega}}^{\theta} \text { and } z_{\omega} \geq \zeta_{\omega},
$$

and her budget constraint in the Tiebout equilibrium under poll taxes is

$$
x+r_{j_{\tilde{\omega}}}^{*} z+\tau_{\tilde{\omega}} \leq w_{j_{\tilde{\omega}}}^{*}\left(\bar{\ell}_{j}^{\theta}-\ell\right)+\sum r_{j_{\tilde{\omega}}}^{*} \bar{L}_{j_{\tilde{\omega}}}^{\theta} .
$$

Since land price is higher under property taxes, the budget constraint under zoning is a subset of the budget constraint under poll taxes (see Figure 2). Since her optimal choice under poll taxes is $\left(x_{\tilde{\omega}}^{\theta}, \ell_{\tilde{\omega}}^{\theta}, z_{\tilde{\omega}}^{\theta}\right)=\left(x_{\tilde{\omega}}^{\theta}, \ell_{\tilde{\omega}}^{\theta}, \zeta_{\omega}\right)$ under the larger budget set, and since $\left(x_{\tilde{\omega}}^{\theta}, \ell_{\tilde{\omega}}^{\theta}, \zeta_{\omega}\right)$ is available under the zoning constraint, her optimal choice under the zoning constraint is $\left(x_{\tilde{\omega}}^{\theta}, \ell_{\tilde{\omega}}^{\theta}, \zeta_{\omega}\right)$ as well. ${ }^{45}$ Now, given this, it is easy to see that each type is optimizing her jurisdiction choice.

What is left is condition 7. Suppose that there is a policy $\omega \in \Omega \backslash \Omega^{*}$ with $t_{\omega} \zeta_{\omega} n_{\omega}>c\left(g_{\omega}\right)$. Suppose that there is a type $\theta \in \Theta$,

$$
\begin{aligned}
& \max _{\omega^{\prime} \in \Omega^{*}} U^{\theta}\left(\omega^{\prime}\right) \\
\leq & \max _{x, \ell} u_{j_{\omega}}^{\theta}\left(x, \ell, \zeta_{\omega}, g_{\omega}, n_{\omega}\right) \quad \text { s.t. } \quad x+\left(r_{j_{\omega}}^{*}+t_{\omega}\right) \zeta_{\omega} \leq w_{j_{\omega}}^{*}\left(\bar{\ell}_{j}^{\theta}-\ell\right)+\sum r_{j_{\omega}}^{*} \bar{L}_{j_{\omega}}^{\theta} .
\end{aligned}
$$

This implies that there exists $\tau_{\omega}=t_{\omega} \zeta_{\omega}$ such that $\tau_{\omega} n_{\omega}>c\left(g_{\omega}\right)$ and

$$
\begin{aligned}
& \max _{\omega^{\prime} \in \Omega^{*}} U^{\theta}\left(\omega^{\prime}\right) \\
\leq & \max _{x, \ell, z} u_{j_{\omega}}^{\theta}\left(x, \ell, z, g_{\omega}, n_{\omega}\right) \quad \text { s.t. } \quad x+r_{j_{\omega}}^{*} z+\tau_{\omega} \leq w_{j_{\omega}}^{*}\left(\bar{\ell}_{j}^{\theta}-\ell\right)+\sum r_{j_{\omega}}^{*} \bar{L}_{j_{\omega}}^{\theta} .
\end{aligned}
$$

However, $\omega$ corresponds to one of $\tilde{\omega} \in \tilde{\Omega}$, and reducing $\tau_{\omega}$ improves consumers' utility. Thus, this contradicts the optimality of jurisdiction choice in the definition of Tiebout equilibrium with poll taxes.

Proposition 4. Every Tiebout equilibrium allocation with entrepreneurial jurisdictions can be supported by a sorting Tiebout equilibrium allocation with poll taxes.

\footnotetext{
${ }^{45}$ Without zoning, she would have wanted to consume less land, but the zoning constraint does not allow this (see Figure 2).
} 
Proof of Proposition 4. With $\left(r_{j}^{*}, w_{j}^{*}\right)_{j \in J}$, and allocation for $\omega \in \Omega^{*}$ and $\theta$ with $m_{\omega}^{\theta}>0$, it is easy to construct the rest of the allocations $\left(m_{\tilde{\omega}}^{\theta}, x_{\tilde{\omega}}^{\theta}, \ell_{\tilde{\omega}}^{\theta}, z_{\tilde{\omega}}^{\theta}\right)_{\theta \in \Theta, \tilde{\omega} \in \tilde{\Omega}}$ for $m_{\omega}^{\theta}=0$ (use condition 1 if the budget set is nonempty for $\theta$ in $\tilde{\omega}$ : otherwise, assign $(0,0,0))$. We show that this allocation is a Tiebout equilibrium with poll taxes.

Suppose that condition 1 of the Tiebout equilibrium with poll taxes is violated. Then, the same must be true for $\tilde{\omega}$ that corresponds to $\omega \in \Omega^{*}$ for $m_{\omega}^{\theta}>0$. Let $(x, \ell, z) \in \mathbb{R}_{+} \times\left[0, \bar{\ell}_{j_{\tilde{\omega}}}^{\theta}\right] \times \mathbb{R}_{+}$be such that

$u_{j_{\tilde{\omega}}}^{\theta}\left(x, \ell, z, g_{\tilde{\omega}}, n_{\tilde{\omega}}\right)>u_{j_{\tilde{\omega}}}^{\theta}\left(x_{\tilde{\omega}}^{\theta}, \ell_{\tilde{\omega}}^{\theta}, z_{\tilde{\omega}}^{\theta}, g_{\tilde{\omega}}, n_{\tilde{\omega}}\right)$ and $\quad x+r_{j_{\tilde{\omega}}}^{*} z+\tau_{\tilde{\omega}} \leq w_{j_{\tilde{\omega}}}^{*}\left(\bar{\ell}_{j}^{\theta}-\ell\right)+\sum r_{j_{\tilde{\omega}}}^{*} \bar{L}_{j_{\tilde{\omega}}}^{\theta}$.

This means that there exist $\tau^{\prime}>\tau_{\omega}$ and $\left(x^{\prime}, \ell^{\prime}, z^{\prime}\right) \in \mathbb{R}_{+} \times\left[0, \bar{\ell}_{j_{\tilde{\omega}}}^{\theta}\right] \times \mathbb{R}_{+}$with

$$
\begin{gathered}
\left(x^{\prime}, \ell^{\prime}, z^{\prime}\right)=\arg \max u_{j_{\tilde{\omega}}}^{\theta}\left(x, \ell, z, g_{\tilde{\omega}}, n_{\tilde{\omega}}\right) \text { s.t. } x^{\prime}+r_{j_{\tilde{\omega}}}^{*} z^{\prime}+\tau^{\prime} \leq w_{j_{\tilde{\omega}}}^{*}\left(\bar{\ell}_{j}^{\theta}-\ell^{\prime}\right)+\sum r_{j_{\tilde{\omega}}}^{*} \bar{L}_{j_{\tilde{\omega}}}^{\theta} \\
u_{j_{\tilde{\omega}}}^{\theta}\left(x^{\prime}, \ell^{\prime}, z^{\prime}, g_{\tilde{\omega}}, n_{\tilde{\omega}}\right) \geq u_{j_{\omega}}^{\theta}\left(x_{\omega}^{\theta}, \ell_{\omega}^{\theta}, \zeta_{\omega}, g_{\omega}, n_{\omega}\right) .
\end{gathered}
$$

Since $\tau_{\omega}=c(\omega) / n_{\omega}$, by letting $\left(j_{\omega^{\prime}}, g_{\omega^{\prime}}, t_{\omega^{\prime}}, \zeta_{\omega^{\prime}}, n_{\omega^{\prime}}\right)=\left(j_{\omega}, g_{\omega}, \frac{\tau_{\omega}}{z^{\prime}}, z^{\prime}, n_{\omega}\right)$, we get

$$
u_{j_{\omega^{\prime}}}^{\theta}\left(x^{\prime}, \ell^{\prime}, \zeta_{\omega^{\prime}}, g_{\omega^{\prime}}, n_{\omega^{\prime}}\right) \geq u_{j_{\omega}}^{\theta}\left(x_{\omega}^{\theta}, \ell_{\omega}^{\theta}, \zeta_{\omega}, g_{\omega}, n_{\omega}\right)
$$

and

$$
x^{\prime}+\left(r_{j_{\omega^{\prime}}}^{*}+t_{\omega^{\prime}}\right) \zeta_{\omega^{\prime}}+\tau^{\prime} \leq w_{j_{\tilde{\omega}}}^{*}\left(\bar{\ell}_{j}^{\theta}-\ell^{\prime}\right)+\sum r_{j_{\tilde{\omega}}}^{*} \bar{L}_{j_{\tilde{\omega}}}^{\theta} .
$$

This means that Condition 7 of the Tiebout equilibrium with entrepreneurial jurisdictions is violated, which is a contradiction. Thus, Condition 1 of the Tiebout equilibrium with poll taxes is satisfied.

Suppose that Condition 2 is violated. Then for some $\theta$ and some $\tilde{\omega}$ with $m_{\tilde{\omega}}^{\theta}>0$, there is a jurisdiction $\tilde{\omega}^{\prime}$ with $m_{\tilde{\omega}}^{\theta}=0$ (otherwise, Condition 2 of the Tiebout equilibrium with entrepreneurial jurisdictions is violated) and

$$
u_{j_{\tilde{\omega}^{\prime}}}^{\theta}\left(x_{\tilde{\omega}^{\prime}}^{\theta}, \ell_{\tilde{\omega}^{\prime}}^{\theta}, z_{\tilde{\omega}^{\prime}}^{\theta}, g_{\tilde{\omega}^{\prime}}, n_{\tilde{\omega}^{\prime}}\right)>u_{j_{\tilde{\omega}}}^{\theta}\left(x_{\tilde{\omega}}^{\theta}, \ell_{\tilde{\omega}}^{\theta}, z_{\tilde{\omega}}^{\theta}, g_{\tilde{\omega}}, n_{\tilde{\omega}}\right) .
$$

However, if so, we can slightly raise $\tau^{\prime}>\tau_{\tilde{\omega}}$ and reduce the consumption vector without altering the above inequality. Then, we can construct a property tax and zoning policy that mimic such an allocation. Thus, Condition 7 of the Tiebout equilibrium with entrepreneurial jurisdictions is violated, and we reach a contradiction again.

Conditions $3,4,5$, and 6 of the Tiebout equilibrium with poll taxes follow directly. 
Proof of Theorem. Propositions 1, 2, 3, and 4 together prove the statement of the theorem.

\section{References}

[1] Allouch, N., J.P. Conley and M.H. Wooders, The Tiebout Hypothesis: On the Existence of Pareto Efficient Competitive Equilibria, (2004), mimeograph.

[2] Aumann, R.J., Markets with a Continuum of Traders, Econometrica 32 (1964), 39-50.

[3] Berliant, M., Equilibrium Models with Land: Criticisms and an Alternative, Regional Science and Urban Economics 15, (1985), 325-340.

[4] Berliant, M., and M. Fujita, Alonso's Discrete Population Model of Land Use: Efficient Allocation and Competitive Equilibria, International Economic Review 33, (1992), 535-566.

[5] Berliant, M. and H. Konishi, The Endogenous Formation of a City: Population Agglomeration and Marketplaces in Location-Specific Production Economy, Regional Science and Urban Economics 30, (2000), 289-324.

[6] Bewley, T. A Critique of Tiebout's Theory of Local Public Expenditures, Econometrica 49, (1981), 713-740.

[7] Brueckner, J. K., Zoning and Property Taxation in a System of Local Governments: Further Analysis, Urban Studies 18, (1981), 113-120.

[8] Buchanan, J. and C. Goetz, Efficiency Limits of Fiscal Mobility: An Assessment of the Tiebout Model, Journal of Public Economics 1, (1972), $25-43$.

[9] Buchanan, J., and R. Wagner, An Efficiency Basis for Federal Fiscal Equalization, in "The Analysis of Public Output," J. Margolis ed., NBER, New York, 1970. 
[10] Conley, J.P., and M.H. Wooders, Taste-Homogeneity of Optimal Jurisdictions in a Tiebout Economy with Crowding Types and Endogenous Educational Investment Choices, Recherche Economiche 50, (1996), 367387.

[11] Debreu, G., "Theory of Value," Wiley, New York, 1959.

[12] Ellickson, B., Competitive Equilibrium with Local Public Goods, Journal of Economic Theory 21, (1979), 46-61.

[13] Ellickson, B., B. Grodal, S. Scotchmer, and W.R. Zame, Clubs and the Market, Econometrica 67, (1999), 1185-1217.

[14] Flatters, F., V. Henderson, and P. Mieszkowski, Public Goods, Efficiency, and Regional Fiscal Equalization, Journal of Public Economics 3, (1974), 99-112.

[15] Fujita, M., "Urban Economic Theory - Land Use and City Size," Cambridge University Press, 1989.

[16] Hamilton, B.W., Zoning and Property Taxation in a System of Local Governments, Urban Studies 12, (1975), 205-211.

[17] Hart, S., W. Hildenbrand and E. Kohlberg, On equilibrium allocations as distributions on the commodity space, Journal of Mathematical Economics 1, (1974), 159-166.

[18] Henderson, J.V., The Sizes and Types of Cities, American Economic Review $64,(1974), 640-656$.

[19] Hildenbrand, W., "Core and Equilibrium in a Large Economy," Princeton Univ. Press, NJ, 1974.

[20] Ichiishi, T., "Game Theory for Economic Analysis," Academic Press, New York, 1983.

[21] Kaneko, M., and M.H. Wooders, The Core of a Game with a Continuum of Players and Finite Coalitions: The Model and Some Results, Mathematical Social Sciences 12, (1986), 105-137. 
[22] Konishi, H., Voting with Ballots and Feet: Existence of Equilibrium in a Local Public Good Economy, Journal of Economic Theory 68, (1996), 480-509.

[23] LaFountain, C., Endogenous City Formation with Production Externalities: Existence of Equilibrium, forthcoming in Journal of Public Economic Theory, (2006).

[24] Magill, M. and W. Shafer, Incomplete Markets, in "Handbook of Mathematical Economics," Vol. 4, (W. Hildenbrand and H. Sonnenschein, eds.) Elsevier Science, Amsteldam, 1991.

[25] Mas-Colell, A., Indivisible Commodities and General Equilibrium Theory, Journal of Economic Theory 16, (1977), 443-456.

[26] Mas-Colell, A., Efficiency and Decentralization in the Pure Theory of Public Goods, Quarterly Journal of Economics 94, (1980), 625-641.

[27] McKenzie, L., On the Existence of General Equilibrium for a Competitive Market, Econometrica 27, (1969), 54-71.

[28] Nechyba, T.J., Existence of Equilibrium and Stratification in Local and Hierarchical Public Good Economies with Property Taxes and Voting, Economic Theory 10, (1997), 277-304.

[29] Pauly, M.V., A Model of Local Government Expenditure and Tax Capitalization, Journal of Public Economics 6, (1976), 231-242.

[30] Rosen, S., Hedonic Prices and Implicit Markets: Product Differentiation in Pure Competition, Journal of Political Economy 82, (1974), 34-55.

[31] Rothschild, M., and J.E. Stiglitz, Equilibrium in Competitive Insurance Markets: An Essay on the Economics of Imperfect Information, Quarterly Journal of Economics 40, (1976), 629-649.

[32] Samuelson, P.A., The Pure Theory of Public Expenditures, Review of Economics and Statistics 36, (1954), 387-389.

[33] Scotchmer, S., Public Goods and the Invisible Hands, in "Modern Public Finance," (J. Quigley and E. Smolensky eds.) Harvard University Press, Cambridge, MA, 1994. 
[34] Sonstelie, J., and R.P. Portney, Profit Maximizing Communities and the Theory of Local Public Expenditure, Journal of Urban Economics 5, (1978), 263-277.

[35] Tiebout, C., A Pure Theory of Local Public Expenditures, Journal of Political Economy 64, (1956), 416-424.

[36] Wheaton, W., Consumer Mobility and Community Tax Bases, Journal of Public Economics 4, (1975), 377-384.

[37] Wildasin, D.E., Preference Revelation and Benefit Pricing for Differentiated Products and Public Goods: Competitive Clubs with Heterogeneous Consumers, mimeo, Department of Economics, Vanderbilt University, 1992.

[38] Wooders, M.H., Equilibria, the Core, and Jurisdiction Structure in Economies with a Local Public Good, Journal of Economic Theory 18, (1978) 328-348.

[39] Wooders, M.H., The Tiebout Hypothesis: Near Optimality in Local Public Good Economy, Econometrica 48 (1980), 1467-1486. 